\title{
Cost distribution and equity of climate policy in Switzerland
}

\author{
Florian Landis (B)
}

\begin{abstract}
Swiss targets for climate policy require significant reductions of emissions by 2050. While such reductions can be achieved in a cost-efficient manner by employing taxes on greenhouse gas emissions, such taxes tend to lead to a regressive distribution of policy cost among households. To counteract such a regressive outcome, tax revenue may be recycled in a progressive way. This paper uses a computable general equilibrium model coupled with a microsimulation of household income and expenditure to examine the policy cost of different carbon tax policies and their distribution across households. I find that in the absence of revenue recycling, emission taxation leads to a regressive distribution of policy cost. I analyze different revenue recycling schemes (per-capita lump-sum transfers, reductions in labor taxation, and reductions in VAT taxation of necessary commodities) and their ability to avoid regressive outcomes.
\end{abstract}

Keywords: Cost-effectiveness, Computable general equilibrium, Microsimulation, Climate policy, Distributional impacts

\section{Introduction}

Different policy options are often compared based on their aggregate cost. In the context of environmental policy, this may not only include the choice of the primary policy instrument for correcting the environmental externality but also the mechanisms to compensate additional spending (in the case of subsidies for environmentally friendly behavior) or revenue (in the case of taxes on polluting activities) by the government from the primary instrument. The literature on the double dividend (Goulder, 1995) has found that the mechanisms for revenue-redistribution can play an important part in keeping overall costs of pollution taxes low. At the same time, it has been recognized that questions of political feasibility, which depend to a large part on the distribution of policy costs across economic agents, competes with overall efficiency for determining the preferred policy (Bovenberg, 1999).

One concern is that if the government taxes the use of greenhouse gas (GHG) emitting fossil fuels, low-income households might pay a disproportionately high share of the policy's cost (Carattini et al., 2017). Analyses of

Correspondence: landisf@ethz.ch

ETH Zürich, ZUE E3, Zürichbergstrasse 18, 8092 Zürich, Switzerland household expenditures indicate that low-income households spend a larger share of their overall expenditures on energy than do households with a higher income in some cases (this depends on country and fuel that are considered) but not in others (Sterner, 2012; Decoster, 1995). In any case, regressive impacts on the expenditure side can be reversed when taking into account revenue recycling options and impacts of policies not only on consumer prices, but also on income. Rausch et al. (2011) highlight the importance of including effects on income effects using a computable general equilibrium (CGE) model of the US economy. And several studies in the European context show that revenue recycling has a crucial effect on overall distributional outcome (e.g., Landis and Heindl, 2016; Speck, 1999).

With this paper, I contribute to the study of the tradeoff between efficiency and equity in designing tax-based climate policy. I couple a CGE model with a microsimulation of household expenditure which gives household level detail in its impact assessment. Employing a social welfare function that incorporates inequality aversion, I am able to show how equity concerns influence the ranking of policy options. While this framework has been previously applied elsewhere (see Böhringer et al., 2017), 
this is the first such analysis in the context of Swiss climate policy. I attempt the first comparison of different revenue recycling options within this framework.

In the Swiss context, Imhof (2012) and Böhringer and Müller (2014) studied the trade-offs between efficiency and equity in designing tax-based climate policy. Using a CGE model of Switzerland and representing household consumption by 5 income quintiles (Böhringer and Müller, 2014) detect a trade-off between efficiency and equity. If carbon tax revenue is used to reduce income taxes, employment increases, which is efficient on the national level, but most of these benefits go to highincome households. Their analysis does not use a social welfare function that takes equity concerns into account, and it cannot rank policies due to this trade-off. Imhof (2012) uses a CGE model representing household consumption by representative agents corresponding to 10 income deciles of working age households and 4 income quartiles of retired households. He finds a trade-off between equity and efficiency as well and uses different assumptions about the appropriate inequality aversion to calibrate welfare functions. If inequality is an issue, it is the recycling scheme with the highest aggregate cost that should be chosen. When using welfare functions that take equity concerns into account combined with rough aggregates of households, however, variation of income and policy impacts within those aggregates is averaged out. Still, in agreement with Imhof's study, my results indicate that revenue recycling via per-capita lump-sum transfers is not the most efficient in terms of aggregate productivity but becomes the preferred among the considered choices if equity is of concern. This can be seen as vindication of the current practice of recycling part of the revenue from climate taxation by lump-sum per-capita refunds to personal health insurance bills. ${ }^{1}$ My results highlight the importance of considering disaggregated households rather than household aggregates when analyzing inequality questions. Also, my results show that the design of revenue recycling may be as important as the concrete design of carbon tax policy if inequality aversion is of concern.

The outline of the remainder of the paper is as follows. In Section 2, I describe the numerical framework which is used to compare the different policy options. Section 3 describes the policy scenarios that are considered in the analysis. Section 4 presents the results of the numerical analysis, and in Section 5, I summarize the main conclusions and compare them with the actual Swiss policy design.

\footnotetext{
${ }^{1}$ About one third of carbon tax revenue is used to finance the Swiss Building Program, which subsidizes investments in improved insulation and non-fossil-based heating systems. From the remainder, the part of the revenue from taxing household fuel use is recycled to inhabitants via this per-capita lump-sum rebate (https://www.bafu.admin.ch/co2-abgabe).
}

\section{Model and data}

This section provides an overview of the quantitative framework which integrates an economy-wide multisector general equilibrium model with a microsimulation analysis of households and has been previously employed by (Landis et al., 2017). I first describe the various data sources used for calibration of the model. A brief description of the model structure and the computation method for solving the economic equilibrium model with a very large number of households are as follows.

\subsection{Data}

The numerical model employed in this study is based on national accounts and household survey data. National accounts provide information on value flows between different sectors of the economy, households, and the government. Household survey data indicates how aggregate household expenditure for different commodities and income from different production factors are distributed among single households. The two data sources were harmonized to construct a balanced set of accounts for the model's base year.

\subsubsection{National economic accounts and energy data}

For the aggregate Swiss economy, value flows are given by the social accounting matrix (SAM) and are complemented by physical energy flow data in the "National Accounting Matrix including Environmental Accounts (NAMEA)" (Nathani et al., 2013). The SAM provides information on economic transactions among firms, households, and government agents. The physical energy flow data allow for inferring $\mathrm{CO}_{2}$ emissions associated with energy demand.

In its original form, the SAM distinguishes 66 industries and commodity groups and 20 categories for final demand. Table 1 provides an overview of the model's commodity aggregation. I identify 11 sectors of energy supply and conversion separating various fuels (motor fuels, heating oil, natural gas, coal, crude oil) and secondary energy carriers (comprising various forms of electricity and heat). The choice of aggregation for the 21 non-energy sectors is guided by the considerations to separately identify sectors which are large in terms of economic size (i.e., contribution to gross value-added), exhibit a high-energy intensity, or sectors that are targeted with specific policy measures (for example, private transportation, household energy demand, and industrial sectors). Three accounts of final demand represent private and government consumption, and investment. The social accounting data further provides payments of payroll taxes, income taxes, valueadded taxes, import tariffs by commodity, sector-specific output taxes, subsidies, and energy-related taxes including mineral oil taxes. 
Table 1 Overview of model resolution: sectors, electricity generation technologies, and household groups

\begin{tabular}{|c|c|}
\hline \multicolumn{2}{|l|}{ Sectors $(i \in I)$} \\
\hline Non-energy & $\begin{array}{l}\text { Agriculture (agr), Paper* (pap), Chemicals* (che), } \\
\text { Plastics* (pla), Other non-metallic mineral } \\
\text { products* (nme), } \\
\text { Basic metals* (bme), Fabricated metal products* } \\
\text { (fmp), } \\
\text { Medical and precision instruments (med), } \\
\text { Manufacturing (man), Machinery and equipment } \\
\text { (mch), } \\
\text { Office machinery, computers (omc), } \\
\text { Radio, TV and communication equipment (elt), } \\
\text { Trade and repair except motor vehicles (wht), } \\
\text { Real estate (est), } \\
\text { Services (ser), Construction (cns), } \\
\text { Final demand public/purchased transport (trc), } \\
\text { Intermediate transportation services (try), } \\
\text { Motor vehicles, trailers (veh), } \\
\text { Trade and repair of vehicles; retail sale of } \\
\text { automotive fuel (trd), } \\
\text { Air transportation* (atp) }\end{array}$ \\
\hline $\begin{array}{l}\text { Energy supply } \\
\text { and conversion }\end{array}$ & $\begin{array}{l}\text { Motor fuels (benz), Heating oil (hoil), } \\
\text { Other mineral oil products (omop), } \\
\text { Nuclear fuel (nuc), Crude oil (cru), Coal* (coa), } \\
\text { Natural gas (gas), Electricity generation* (ele), } \\
\text { Electricity distribution \& transmission (edt), } \\
\text { Electricity from waste incineration* (ewi), } \\
\text { Heat from waste incineration* (hwi) }\end{array}$ \\
\hline Final demand & $\begin{array}{l}\text { Private consumption by representative household, } \\
\text { government consumption, investment demand }\end{array}$ \\
\hline Electricity generation & $\begin{array}{l}\text { Hydro power, Nuclear power, Power from } \\
\text { technologies }(p \in P) \text { fossil fuels, } \\
\text { Power from renewable energy sources }\end{array}$ \\
\hline
\end{tabular}

*Indicates sectors that are subject to the Swiss Emissions Trading System (ETS) which covers energy-intensive industries

\subsubsection{Micro-household data and data reconciliation}

On the household side, a representative sample of the Swiss population of households is portrayed by the 20092011 Swiss Household Budget Survey "Haushaltsbudgeterhebung." The HABE survey is conducted on an annual basis by the Swiss Federal Statistical Office (BFS). It collects information for roughly 3000 households on expenditure patterns and income sources. Household data is weighted according to the inclusion probability. ${ }^{2}$ The weights are adjusted for sampling bias and calibrated to the observed distribution of the Swiss population (BFS, 2007). To increase the sample size, the underlying data set aggregates three waves of survey data from the consecutive years 2009-2011 (BFS, 2012a, 2012b, and 2013) using annual weights. Thus, a set of 9734 observations of household accounts are available to describe household expenditure and income in the model. Besides the

\footnotetext{
${ }^{2}$ The inclusion probability of a member of the population is its probability of becoming part of the sample during the drawing of a single sample.
}

information on income expenditure, the HABE data include other information such as household composition, age of household members, urbanization degree, and ownership status of housing.

The weighted sum of income and expenditures of households reported in $\mathrm{HABE}$ has to be reconciled with the national accounts in the SAM. A match between national aggregates and household-based data in the base year calibration of the model is required for consistent evaluation of counterfactual scenarios. ${ }^{3}$ In a first step, missing data are imputed based on information about households' expenditures and socio-economic characteristics (income, renting or owning a house, etc.). ${ }^{4}$ In a second step, the national consumption in terms of COICOP "Classification of Individual Consumption According to Purpose" categories was then imposed on the household data by scaling the weighted household consumption from the survey by the respective factor for each consumption category. Similarly, household data on wage income was scaled to meet the national aggregate. ${ }^{5}$ Transfers are also in the household survey and were scaled to match aggregate transfers between households and the government from the SAM. The remaining difference between income and expenditure of households was attributed to (dis-)savings. The different adjustments that had to me made are summarized in Table 12 in Appendix 3.

\subsection{Model overview}

Herein, I briefly outline the main key features of the numerical model. Appendix 3 contains a complete algebraic description of the model's equilibrium conditions.

\subsubsection{Heterogeneous households}

All 9734 households from the HABE survey are represented as individual economic agents in the general equilibrium model. This enables me to account for the heterogeneity of the entire Swiss household population along the two dimensions, expenditure and income. The utility functions of households are calibrated such that the observed expenditures at initial prices according to the (harmonized) HABE data are consistent with utility

\footnotetext{
${ }^{3}$ The aggregated household consumption in the HABE and SAM accounts can differ significantly for several reasons: (i) missing households: in contrary to the national accounts, the HABE data does not consider non-profit institutions serving households (NPISH) and collective households; (ii) differences in definition of cost (for example, health care and education expenditure); (iii) missing response on certain questions; and (iv) misreported items (for example, expenditures on alcohol).

${ }^{4}$ For more information on imputation techniques, see, for example, Bethlehem et al. (2011) and Rubin (1987). Imputation was used to correct incomplete observations in the HABE data with respect to thermal fuel consumption of households, for which an unrealistically high share of households does not report any spending.

${ }^{5}$ Operating surplus of economic sectors includes profits that are directly reinvested, and thus, a direct link to capital rents of investors cannot be made. Based on historical observations, about half of the operating surplus generates actual income to households, while the remainder is directly reinvested.
} 
maximization of households given market prices. Labor supply, endowments of capital, and entitlements to government transfers are distributed such that the income patterns in the HABE data are achieved.

For counterfactual scenarios, the model fixes labor supply and savings at business-as-usual levels. Household savings are used for purchasing a composite investment good. Given goods' and factors' prices, households maximize their utility by allocating income received from government transfers, wages, and rents on capital to consumption. Utility from consumption is described by a nested constant-elasticity-of-substitution (CES) utility function (see the upper panel in Figure 8 in Appendix 3). The utility function uses the same elasticities of substitution for all households, and in order to capture the increasing ability in the long term to adopt to fundamental economic change, select elasticities are set higher in 2035 and 2050 than up to 2020. The specific elasticities of substitution in household consumption can be found in Table 11 in Appendix 3.

\subsubsection{Production technologies and firm behavior}

In each industry, gross output is produced using primary inputs of labor and capital together with intermediate inputs that are composed of domestically produced goods and imported goods. The model employs CES functions to characterize the substitutability between inputs of production (see the lower panel in Figure 8 in Appendix 3). Given input prices (gross of taxes and subsidies), firms minimize production costs subject to physical technology constraints. Firms operate in perfectly competitive markets selling their products at a price equal to marginal costs. Capital and labor are assumed to be mobile across Swiss industries. I assume that Swiss and foreign investors view investments inside or outside Switzerland as perfect substitutes. This implies that rents on capital are determined by the international interest rate on which Swiss policy has no effect.

Power generation is modeled using a compact bottomup activity analysis representation where discrete technologies produce a homogeneous electricity good by combining technology-specific capital with inputs of labor, fuel, and materials. The substitution elasticity between technology-specific capital, and the composite inputs is chosen to match exogenous technology-specific price elasticities of supply. The national accounts provide data to calibrate production functions for electricitygenerating technologies that have been active in the base year 2008: hydro power, nuclear power, power from renewables, and power from fossil fuels.

\subsubsection{Government activity}

A single government entity represents government activities at all levels-federal, cantonal, and local-as well as part of the social security system. The government collects taxes to finance transfers and the provision of a public good. Besides value-added taxes, income taxes, corporate profit taxes and social security contributions, the model features industry-specific output taxes, and subsidies as well as import and export levies. The public good is produced with commodities purchased at market prices. The economic impact assessment of different policy scenarios always involves revenue-neutral tax reforms in order to keep the provision of the public good constant. Thus, I can provide a meaningful welfare comparison without the need to trade off private and government (public) consumption. Revenue neutrality is achieved by endogenously setting aggregate amounts of lump-sum transfers between the government and households. The lump-sum transfers are allocated among households in proportion to base year household consumption. ${ }^{6}$

\subsubsection{International trade and model closure}

With the exception of crude oil, which is treated as a homogeneous good, domestic and imported varieties of the same good are differentiated following the Armington (1969) assumption (i.e., for each commodity, its total market supply is a CES composite of a domestically produced variety and an imported variety). In analogy to the import side, domestically produced goods are converted through a constant-elasticity-of-transformation function into goods destined for the domestic market and the export market, respectively.

In international trade, Switzerland is assumed to be small, implying that the levels of Swiss exports and imports do not affect world market prices. Switzerland holds its balance-of-payments (measured in foreign exchange) constant across policy scenarios, and the exchange rate adjusts endogenously to reflect changes in terms of trade.

\section{Scenarios}

The analysis conducted for this paper establishes a business as ausual (BAU) scenario in which currently implemented policies are assumed to be continued. The model is calibrated to assumptions about how energy prices and demand develop under the currently implemented policies. Counterfactual scenarios then implement different additional policies for reaching targets of Swiss energy and climate policy and compare socio-economic outcomes in these counterfactual scenarios with the outcomes in the BAU.

\footnotetext{
${ }^{6}$ This mechanism for ensuring revenue neutrality balances the national budget but not necessarily budgets at the cantonal level. My model neglects the changes in cantonal revenue from changes in wages and capital rents and thus income tax payments. Due to different income tax rates, different cantons are affected to different degrees by these tax revenue impacts of climate policy. As it stands, my model generates results that could only be achieved if additional transfer payments between cantons would be enacted.
} 
Independent of the considered policy scenario, the Swiss economy is facing world market prices for trade in energy goods and population growth as given in Table 2 . Population growth was used to compute the total $\mathrm{CO}_{2}$ emission targets for Switzerland from the per-capita targets currently specified. ${ }^{7}$

\subsection{Business-as-usual (BAU) scenario}

The BAU includes all currently implemented policies for reducing $\mathrm{CO}_{2}$ emissions in Switzerland. Some instruments such as the "Gebäudeprogramm/Programme Bâtiments" (subsidies on buildings insulation) and the "Wettbewerbliche Ausschreibung/Appels d'offres publics" (competitive bidding for state support of energy efficiency measures) but also efficiency standards on vehicles and appliances are not explicitly implemented in the CEPE$\mathrm{HH}$ model but have implicit consequences on the adopted assumptions about energy demand over time in the BAU. Price-based policies such as electricity and $\mathrm{CO}_{2}$ taxes are explicitly modeled, and the model is calibrated such that $\mathrm{BAU}$ energy demand trends are consistent with $\mathrm{BAU} \mathrm{CO}_{2}$ prices (both given in Table 3). The Swiss Emission Trading System (CH ETS) is assumed to remain uncoupled with the European Emission Trading System (EU ETS) in the BAU scenario. Energy demand by ETS sectors has been calibrated such that the scenario trajectories of fossil fuel demand within the ETS sectors (see fourth line in Table 3) would be consistent with EU ETS market prices (fifth line in Table 2). As these trends for fossil energy demand imply emissions in excess of what the cap for the $\mathrm{CH}$ ETS foresees, the model, by restricting ETS emissions to the cap, determines the endogenous ETS permit prices in Switzerland in the BAU scenario.

Distributional impacts of carbon taxes are to a large extent determined by how much households spend on fossil fuels and thus by how much they emit. Figure 1 shows shares of household expenditures going toward fossil fuels where households are grouped by income quintile. The fact that low-income households tend to spend large shares on fossil fuels implies that a carbon tax without appropriate corrective revenue recycling results in a regressive distribution of policy cost.

The point that this study makes is that the distribution of policy cost relative to baseline household welfare depends on the revenue recycling scheme that is used. The impacts of different revenue recycling schemes, in turn, depend on household size if revenue recycling is per-capita-based, on labor income if revenue recycling reduces labor taxes, and on expenditure for certain goods if revenue recycling reduces VAT on those goods. Appendix 1 shows how these indicators are distributed across income in the BAU.

\footnotetext{
${ }^{7}$ The growth of (the effective value of) the labor force was chosen in line with BAU growth of gross domestic product (GDP), on the other hand.
}

Table 2 Time trends of exogenous parameters facing the Swiss economy in all scenarios

\begin{tabular}{lllll}
\hline & 2010 & 2020 & 2035 & 2050 \\
\hline Population (million) & 7.79 & 8.68 & 9.8 & 10.3 \\
Crude oil price (2010 US\$/barrel) & 78 & 105 & 120 & 129 \\
Gas price (2010 US\$/MBtu) & 7.5 & 10.4 & 11.7 & 12.4 \\
EU electricity prices (2013€/MWh) & 133 & 150 & 160 & 159 \\
EU ETS permit price (2010 €/tCO2e) & 15 & 15 & 57 & 239
\end{tabular}

Note: Scenario drivers were given by the Swiss Energy Modelling Platform (SEMP). For sources of scenarios see Landis, Marcucci, et al. (2018)

\subsection{Counterfactual scenarios}

15TPC The policy target in this scenario is to reduce emissions to 1.5 metric tonnes of $\mathrm{CO}_{2}$ equivalent (tCO2e) per capita across the Swiss population. The target is reached by an perfectly informed government that sets a uniform carbon tax such that the target for 2050 is reached. For the years leading up to 2050, a succession of annually decreasing emission targets are given by the scenario (see Table 4). Revenue from carbon taxation of industries is returned to them via a reduction of social contribution in proportion to their wage bills. Revenue from taxing $\mathrm{CO}_{2}$ emissions by households is returned as a per-capita lump-sum transfer.

10TPC Same as 15TPC but with annual targets leading up to 1.0 tCO2e per capital in 2050. Emission targets for 2035 and 2050 relative to 2010 are given in Table 4.

XXTPC_etsUni Scenarios 15TPC_etsUni and 10TPC_etsUni reach the same targets as scenarios 15TPC and 10TPC, but different policies are implemented: An emissions trading system (ETS) caps the emissions of industrial sectors included in the system while the government sets uniform $\mathrm{CO}_{2}$ taxes outside the ETS such that the overall emission target of the respective scenario is met.

Table 3 Time trends of Swiss economic indicators and policies in the BAU scenarios

\begin{tabular}{lllll}
\hline & 2010 & 2015 & 2035 & 2050 \\
\hline GDP (relative to 2010) & 1 & 1.046 & 1.43 & 1.66 \\
Energy demand (rel. 2010) & 1 & 0.92 & 0.839 & 0.782 \\
Electricity demand (rel. 2010) & 1 & 0.996 & 1.097 & 1.175 \\
Fossil energy demand in ETS (rel. 2010) & 1 & 0.876 & 0.621 & 0.388 \\
$\mathrm{CO}_{2}$ tax on thermal fuels (CHF/tCO 2$)$ & 36 & 60 & 120 & 120 \\
$\mathrm{CO}_{2}$ tax on motor fuels (CHF/tCO 2$)$ & 0 & 0 & 0 & 0 \\
Cap in Swiss ETS & $\mathrm{NA}$ & 0.965 & 0.617 & 0.356 \\
(relative to 2013 emissions) & & & & \\
\hline
\end{tabular}

Note: Scenario drivers were given by the SEMP. For sources of scenarios, see Landis, Marcucci, et al. (2018). CHF denotes the currency Swiss Francs 

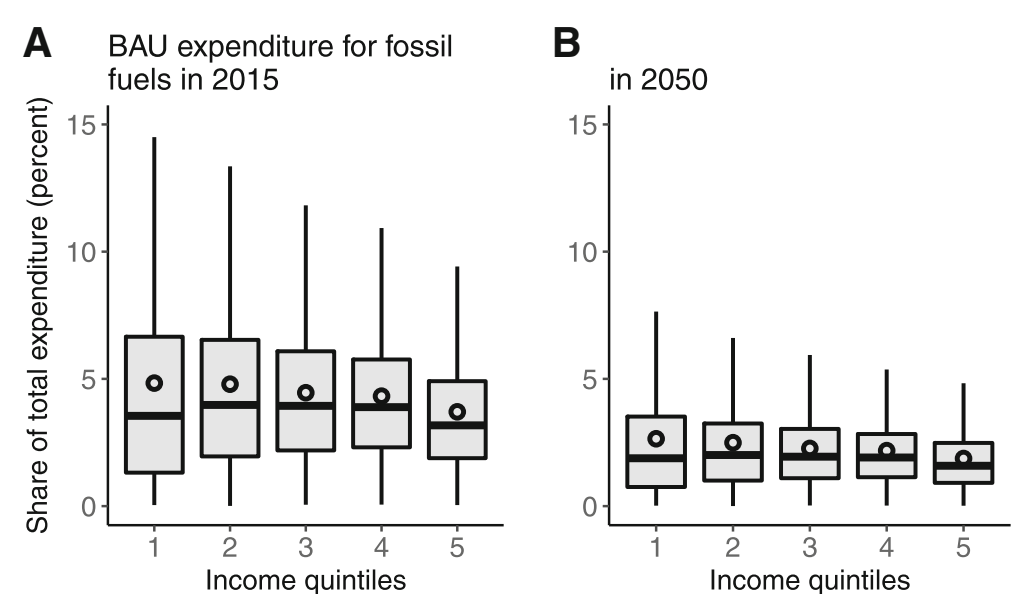

Fig. 1 Distribution of fossil fuel expenditure share within and across income quintiles in 2015 (a) and 2050 (b). Note: Income quintiles are according to allocation by statistical office. Circles show mean values

XXTPC_etsDiff Scenarios 15TPC_etsDiff and 10TPC_etsDiff resemble scenarios $15 \mathrm{TPC}$ _etsUni and 10TPC_etsUni, but instead of taxing emissions outside the ETS uniformly, they put a four times lower tax on motor fuels than on thermal fuels. The absolute level of the taxes in each year is again chosen to meet the annual emission targets.

XXTPC_etsXxx_LT Instead of a lump-sum transfer for recycling revenue from taxing GHG emissions by households, these scenarios employ a reduction of labor taxation for returning the revenue. Note that these taxes do not influence labor supply decisions in my model and thus do not create the efficiency gain expected in the double-dividend literature. ${ }^{8}$

XXTPC_etsXxx_VAT Instead of a lump-sum transfer for recycling revenue from taxing GHG emissions by households, these scenarios employ a reduction of the VAT rate for the commodities AGR and TRC for returning the revenue. $A G R$ and TRC are the two commodities that my model resolves for which VAT is clearly regressive: low-income households tend to spend a larger share of their expenditures on these goods than do high-income households. I show the expenditure shares across income quintiles in Figure 6 in Appendix 1.

It is important to note that revenue recycling does not make carbon policy revenue-neutral. While the recycled amount compensated the revenue from carbon taxation, climate policy impacts other revenue channels of government income. In order to compensate these changes, the

\footnotetext{
${ }^{8}$ The standard way to model labor supply decisions is to include leisure time in consumer utility. This then creates a trade-off between leisure and labor, resulting in labor supply responses to changes in wages. I cannot calibrate the value of the full-time endowment on the household level as the household's labor supply in hours, and thus, the value to the household of $1 \mathrm{~h}$ is unknown.
}

government in the model levies a uniform tax on income net of baseline taxes. As it is unclear what measures the Swiss government would employ in the real world to balance its budget, this method of balancing government income is chosen to make sure that budget balancing does not have biased impacts on the distributional outcome of the scenario results.

\section{Results}

Before showing and discussing results on equivalent income and social welfare, I shall highlight the amount of revenue that is generated by the carbon tax in the different scenarios and what changes in tax rates or transfers this results in (see Table 5). The first row shows that rates for the economy-wide uniform taxation of carbon do not change much across different recycling mechanisms and that they reach just below CHF 950 per $\mathrm{tCO}_{2}$ in 2050 in the case of the ambitious target of scenario 10TPC. The revenue that is recycled on the household side is shown in the following rows for the different schemes of carbon taxation, uniform, etsDiff, and etsUni. The variation across taxation schemes of the amount of money for recycling is reflected in different results for the recycling mechanisms. The third row from the bottom shows that per-capita lump-sum transfers might reach as high as CHF 440 per annum by 2050 with the ambitious target of the 10TPC scenario. To compare this with transfers from the current $\mathrm{CO}_{2}$ levy, consider that it has been determined that

Table 4 Emission targets for policy scenarios

\begin{tabular}{llll}
\hline Target (relative to 2010) & 2010 & 2035 & 2050 \\
\hline 15TPC & 1 & 0.571 & 0.284 \\
10TPC & 1 & 0.510 & 0.189 \\
\hline
\end{tabular}


Table 5 Carbon taxes, volumes of revenue for recycling, and the resulting changes in recycling mechanisms for the different scenarios

\begin{tabular}{llllll}
\hline & & 2035 & & 2050 \\
& & $15 T P C$ & $10 T P C$ & $15 T P C$ & 10TPC \\
\hline $\begin{array}{llllll}\text { Carbon tax } \\
\text { (CHF/tCO2) }\end{array}$ & uniform & $234-235$ & $336-339$ & $516-517$ & $943-946$ \\
Revenue & uniform/LS & 3.19 & 4.03 & 3.56 & 4.47 \\
(billion CHF) & etsDiff/LS & 2.89 & 3.71 & 3.35 & 4.05 \\
& etsUni/LS & 3.38 & 4.31 & 3.64 & 4.51 \\
LS: transfers & (CHF) & $295-345$ & $379-440$ & $326-353$ & $393-438$ \\
LT: reduction & $\%$ change & $0.7-0.9 \%$ & $1.0-1.1 \%$ & $0.7-0.8 \%$ & $0.9-1.0 \%$ \\
VAT reduction & $\%$ change & $2.1-2.5 \%$ & $2.7-3.2 \%$ & $2.1-2.3 \%$ & $2.5-2.8 \%$ \\
\hline
\end{tabular}

Note: The ranges of carbon tax rates on the first row cover the different recycling mechanisms LS, LT, and VAT for an economy-wide uniform carbon tax. The ranges of transfers and tax reductions (three bottom rows) cover the different carbon tax schemes uniform, etsDiff, and etsUni

in 2019, the per-capita refund shall be CHF $76.80 .{ }^{9}$ The bottom two rows show the reductions in the taxation of labor and VAT. Labor tax reductions do not exceed 1.1 percentage points, which leaves positive contributions to social security if this is deducted from the current rate of contribution of $5.625 \%$ or more that employees have to pay. ${ }^{10}$ VAT reductions on the other hand go as high as 3.2 percentage points. Given that this reduction is applied to agricultural products (AGR) among others, the going VAT rate on which is $2.5 \%,{ }^{11}$ this would lead to negative VAT taxation, thus ruling out the proposed VAT recycling as a practicable way of recycling carbon tax revenue in practice. The recycling via VAT could, however, be modified to yield lower percentage point reductions by including more commodities for the reduction of the VAT.

When reporting results on how the different policy options perform, I first discuss scenario outcomes in terms of mean income (MI), a measure of macroeconomic production efficiency that does not factor in considerations of equity. I then go on to evaluate mean equivalent income (MEI) as a combined measure of production and consumption efficiency: MEI values income to large households more than income of small households, as the sharing of consumption goods in large households yields higher utility from a given amount of income (i.e., household consumption display increasing economies of scale). After that, welfare impacts across income quintiles illustrate how impacts are distributed across income

\footnotetext{
${ }^{9}$ This is according to a communication by the Federal Office for the Environment (BAFU) from August 2018 to be found at https://www.bafu. admin.ch/co2-abgabe (accessed 9 October 2018).

${ }^{10}$ https://www.bsv.admin.ch/bsv/de/home/sozialversicherungen/ueberblick/ beitraege.html

${ }^{11}$ https://www.estv.admin.ch/estv/de/home/mehrwertsteuer/

fachinformationen/steuersaetze.html
}

and the Atkinson index is used as a measure of distributional fairness for comparing and ranking policy options taking both efficiency and equity into account. While different indices of inequality exist (popular among them are the Lorenz curve (a graphical representation of inequality) and the Gini coefficient), the Atkinson index is a prominent example of an index that allows for the ranking of policy outcomes if the policies have impacts on both equality and social welfare (Subramanian, 2007). The Atkinson index does not readily let itself be interpreted as a measure of inequality but represents the degree of aversion to inequality present in a given situation. The central parameter of inequality aversion of the Atkinson index can be measured empirically and the literature on this subject provides ranges of values that this parameter plausibly may take.

\subsection{Mean income}

MI is defined as the mean income across the population where all household members are assumed to benefit from household income as if this income where equally distributed among household members:

$$
\mathrm{MI}=\frac{\sum_{h} w_{h} s_{h} \frac{Y_{0}+E V_{h}}{s_{h}}}{\sum_{h} w_{h} s_{h}},
$$

where $w_{h}$ and $s_{h}$ are statistical weight and size of household $h . Y_{0}$ is household income in the BAU scenario and $E V_{h}$ is equivalent variation: the change in income at BAU prices that would have resulted in the same consumption utility as does the scenario impacts.

This measure of income is a linear transformation of aggregate $\mathrm{EV} \sum_{h} w_{h} E V_{h}$ and will rank scenario outcomes that same way a model with one aggregate household would. The ranking reflects the efficiency of the economy in producing the goods that households value. The results therefore are directly comparable with previous studies that employ such aggregate households. In particular, Table 6 shows that the trade-offs between different carbon tax designs look similar as in Landis, Rausch, et al. (2018). Specifically, the differentiation of carbon tax rates on motor and thermal fuels is efficient for early years and less ambitious targets. This is due to considerable pre-existing taxes on motor fuels that distort the initial economy and make additional abatement in the transport sector expensive (Bovenberg and Goulder, 1996; Landis, Rausch, et al. 2018). By 2050, uniform taxation of carbon across fuels and sectors is the most efficient policy (among those evaluated) for both levels of ambition of climate policy.

It merits analyzing changes $\mathrm{MI}$ across different recycling schemes in order to see how revenue recycling affects the economy's productivity. The results in Table 6 make it clear that recycling carbon tax revenue through per-capita lump-sum payments (scenarios LS) consistently results 
Table 6 Percentage change of MI from BAU for different years and scenarios

\begin{tabular}{|c|c|c|c|c|c|c|}
\hline & \multicolumn{3}{|c|}{2035} & \multicolumn{3}{|c|}{2050} \\
\hline & Uniform & etsDiff & etsUni & Uniform & etsDiff & etsUni \\
\hline \multicolumn{7}{|c|}{$15 T P C$} \\
\hline$\angle S$ & -0.295 & -0.263 & -0.311 & -0.862 & -0.869 & -0.876 \\
\hline LT & -0.269 & -0.238 & -0.283 & -0.836 & -0.844 & -0.850 \\
\hline VAT & -0.281 & -0.249 & -0.296 & -0.841 & -0.849 & -0.856 \\
\hline \multicolumn{7}{|c|}{ 10TPC } \\
\hline$\angle S$ & -0.497 & -0.487 & -0.531 & -1.458 & -1.580 & -1.524 \\
\hline LT & -0.463 & -0.456 & -0.495 & -1.426 & -1.551 & -1.491 \\
\hline VAT & -0.483 & -0.473 & -0.517 & -1.438 & -1.561 & -1.504 \\
\hline
\end{tabular}

in the least efficient outcome of the three options in terms of productivity. As consistently, the labor tax reduction (in scenarios LT) looks to produce outcomes where productivity is highest.

To understand what drives the differences between the per-capita lump-sum recycling and the recycling via labor tax reductions, consider that, in my model, labor tax reductions have no direct impact on the efficiency of labor allocation: labor supply is fixed and the wage rate (remuneration of labor before taxation) is determined by the marginal productivity of labor. In the stylized world of my model, therefore, a labor tax reduction is functionally equivalent to a lump-sum payment. Recycling schemes LS and LT only differ by which households are reached by the effective lump-sum payments to what extent. Analyzing to what extent income is made up by labor (Figure 6 in Appendix 1 shows that high-income households earn a bigger part of their income from labor than low income households) and considering that a per-capita payments increase relative income more for low-income households, one sees that LS recycling tends to increase spending for low-income households while LT recycling increases that of high-income households. Figure 1 shows that its the low-income households that tend to have the more fossil fuel-intensive consumption. By promoting the consumption of households that demand relatively more fossil fuels, the LS recycling thus creates additional pressure on the production sector to abate emissions and thus decreases the productive efficiency of the economy relative to the LT recycling.

The VAT recycling, finally, distorts consumption choices by not affecting all consumption goods to the same degree and tends to increase the spending power of low-income households more than that of high-income ones (see Figure 5 in Appendix 1). Both effects point toward low efficiency, but the model results show that the overall effect is still better than under LS recycling.

\subsection{Mean equivalent income}

The definition of MEI

$$
\mathrm{MEI}=\frac{\sum_{h} w_{h} s_{h} \frac{Y_{0}+E V_{h}}{\sqrt{s_{h}}}}{\sum_{h} w_{h} s_{h}}
$$

uses the same weighting of average household values as MI but takes the mean of household equivalent income which takes economies of scale in consumption into account: household $h$ 's real income $Y_{0}+E V_{h}$ is divided by $\sqrt{s_{h}}$. This measure thus takes both efficiency of production and efficiency of consumption into account. ${ }^{12}$

Table 7 shows that MEI ranks the three design of carbon taxation the same way as MI. But when looking at the ranking of recycling schemes, it becomes evident that the LS recycling gets an important boost by considering the efficiency of consumption. Under per-capita lump-sum recycling, refunds are given in proportion to the size of the household, which is the same parameter that drives the economies of scale of consumption. At the same time, labor tax reduction tend to reach high-income households with their high shares of wages in overall income. These households tend to be bigger than low-income households, but the relation between refunds and household size is not as direct as in the LS scenarios. The VAT recycling, finally, is worst at allocating refunds to large households: While LT distributed revenue in proportion to labor income (with high-income shares for the larger high-income households) VAT recycling gives comparably more to (on average smaller) low-income households with their bigger fossil fuel expenditure.

It should be noted that the advantage that the LS recycling has over the LT recycling, while consistent across years, targets, and carbon tax designs, is small. The main conclusion from assessing policy scenarios through the lens of MEI would be that VAT recycling should be avoided.

\subsection{Distributional impacts and social welfare}

Empirical evidence suggests that consumers value a given amount of additional income more if they are in a situation when their income is low than if it is high (see, e.g.) (Layard et al., 2008) and references therein). Other results point to the fact that in a societal context, people display some inequality aversion and prefer outcomes where wealth is more equally distributed (Carlsson et al., 2005; Fehr and Schmidt, 1999).

My results indicate that different revenue recycling methods result in different distributions of policy cost

\footnotetext{
${ }^{12}$ Between households with the same expenditure structure, MEI would find it efficient to allocate all income from small households to that of large households, as these generate more equivalent income from nominal income than do small ones. It is only by introducing inequality aversion in the social welfare function that a trade-off between efficient consumption by large households and the aversion of starving small households from income can be made.
} 
Table 7 Percentage change of MEl from BAU for different years and scenarios

\begin{tabular}{lllllll}
\hline & $\begin{array}{l}2035 \\
\text { uniform }\end{array}$ & etsDiff & etsUni & uniform & etsDiff & etsUni \\
\hline 15TPC & & & & & & \\
LS & -0.269 & -0.236 & -0.282 & -0.831 & -0.835 & -0.843 \\
LT & -0.271 & -0.237 & -0.283 & -0.833 & -0.836 & -0.845 \\
VAT & -0.291 & -0.255 & -0.305 & -0.846 & -0.848 & -0.858 \\
10TPC & & & & & & \\
LS & -0.458 & -0.446 & -0.487 & -1.415 & -1.534 & -1.476 \\
LT & -0.460 & -0.447 & -0.489 & -1.416 & -1.535 & -1.478 \\
VAT & -0.489 & -0.474 & -0.522 & -1.438 & -1.554 & -1.500 \\
\hline
\end{tabular}

Note: Choices of recycling schemes and carbon tax design that yield the highest $\mathrm{MEl}$ are in bold, and choices that yield the lowest MEl are in italic font

among households of different income quintiles. Figures 2 and 3 illustrate this for the scenarios 15TPC and 10TPC and the years 2035 and 2050. While the distribution of policy cost is progressive if revenue is returned via a lumpsum per-capita refund, labor tax reductions result in a regressive distribution of policy cost and VAT reductions in an almost neutral but still slightly regressive distribution.

MEI as a measure of average welfare does not consider inequality, but it can be modified it by the Atkinson index $A_{\varepsilon}$ to construct a social welfare function that takes inequality into account (Atkinson, 1970):

$$
\mathrm{SW}=\mathrm{MEI} \times\left(1-A_{\varepsilon}\right),
$$

with

$$
A_{\varepsilon}=1-\frac{1}{\mathrm{MEI}}\left[\frac{\sum_{h} w_{h} s_{h}\left(\frac{Y_{0}+E V_{h}}{\sqrt{s_{h}}}\right)^{1-\varepsilon}}{\sum_{h} w_{h} s_{h}}\right]^{\frac{1}{1-\varepsilon}}
$$

and where I chose $\varepsilon=1.25 .{ }^{13}$ Social welfare simplifies to

$$
\mathrm{SW}=\left[\frac{\sum_{h} w_{h} s_{h}\left(\frac{Y_{0}+E V_{h}}{\sqrt{s_{h}}}\right)^{1-\varepsilon}}{\sum_{h} w_{h} s_{h}}\right]^{\frac{1}{1-\varepsilon}} .
$$

If I include inequality aversion via an Atkinson index, the ranking of the recycling methods changes (see Table 8). The per-capita lump-sum recycling now yields the best results for all policy scenarios and by a wide margin. Intuitively, per-capita lump-sum recycling helps low-income households the most and thus lowers the Atkinson index, because the index gives the losses or gains of low-income households more weight. The overall results for social welfare in Table 8 and comparison with Table 7 imply that switching from labor tax reduction to lump-sum transfers reduces inequality aversion and thus the Atkinson index.

\footnotetext{
${ }^{13}$ This is very close to the central estimate found by (Layard et al., 2008) and similar to the upper value used by (Creedy and Sleeman, 2006).
}

But including inequality aversion in my analysis not only affects the ranking of revenue recycling schemes but also that of tax design. If tax design is chosen based on MI, the scenarios 15TPC_etsDiff and 10TPC_etsDiff are preferable to the respective uniform tax scenarios in 2035. But based on social welfare, and thus considering inequality aversion, the uniform tax scenarios are always to be preferred if taxes are recycled via per-capita lump-sum transfers. This becomes plausible if one considers that under tax differentiation, a higher burden is placed on taxation of thermal fuels, which is notably regressive on the expenditure side while taxation of motor fuels (which is progressive) is eased (Landis, Rausch, et al. 2018). Comparing the impact on social welfare of carbon tax design choice and recycling scheme choice shows that the latter is the more important.

The parametrization of inequality aversion is not straightforward and different studies have come up with a range of estimates (Layard et al., 2008). In order to account for uncertainty about the correct value of inequality aversion to employ in evaluation of social welfare, I report social welfare results for alternative choices of $\varepsilon$ for computing the Atkinson index in Appendix 2. Reflecting lower and upper bound estimates of inequality aversion in subgroups of the sample surveyed by Layard et al. (2008), I choose $\varepsilon=0.85$ and $\varepsilon=1.85$ as lower and upper bound estimates of inequality aversion. For both choices, uniform carbon taxation with per-capita lump-sum transfers remains the best policy option across years 2035 and 2050 and targets 15TPC and 10TPC.

\section{Conclusions}

This paper analyses different policy options for reaching Switzerland's climate targets for 2050. It considers different versions of carbon pricing and different schemes for returning carbon tax revenue back to households. The results are analyzed both in terms of economic efficiency by looking at mean real income of Swiss residents and in terms of equity by comparing outcomes across scenarios in terms of a social welfare function that values financial gains by low-income households more than the same gains by high-income households.

I find that the differentiation of carbon tax rates between motor fuels and thermal fuels, while beneficial in terms of production efficiency, are not favored if consumption efficiency and inequality aversion are factored in. I find this conclusion to be stable across the range of plausible degrees of inequality aversion.

When I compare different recycling schemes, I find that (i) the choice of recycling scheme has the larger influence on social welfare (considering inequality aversion) than does the choice of carbon taxing framework and (ii) that there is an efficiency-equity trade-off in choosing the revenue recycling scheme and that the equity concerns 

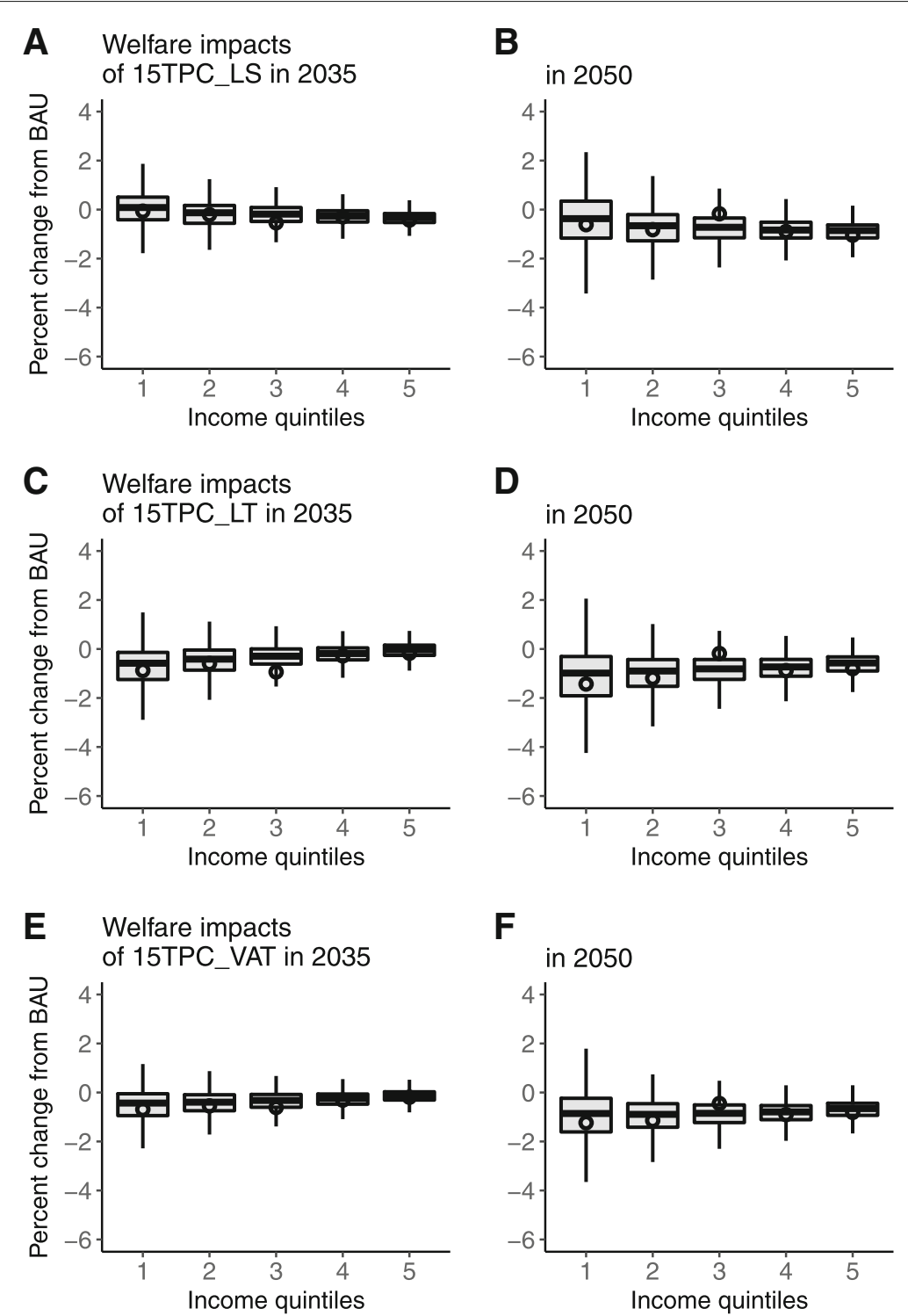

Fig. 2 Distribution of welfare impacts across income quintiles for different revenue recycling schemes (15TPC target) in 2035 (a, c, and e) and 2050 $(\mathbf{b}, \mathbf{d}$, and $\mathbf{f})$

drive the decision. With the currently implemented percapita lump-sum transfers for recycling the tax revenue, climate policy costs low-income households less than it does high-income households. This effect would be less pronounced or even reversed if the revenue were recycled via reductions in labor taxation or VAT taxes on necessary goods. Assuming a social welfare function that incorporates inequality aversion and thus values decreased losses by members of low-income households more than the increased losses by members of high-income households, I find that per-capita lump-sum revenue recycling is the best of the considered choices. The textbook argument for focusing on aggregate national income implies that wealth could be redistributed in a lump-sum fashion even from the VAT reduction outcome. But lacking the political means of implementing such transfers, the trade-off between aggregate efficiency and equity persists and the lump-sum transfers (currently implemented in Switzerland) seem to be a reasonable choice.

A shortcoming of my model is that it cannot represent the benefits from labor tax reductions predicted by the literature on the double dividend. ${ }^{14}$ This is due to missing information about labor supply decisions on the household level. As revenue recycling in the form of labor tax reductions result in increased inequality, the

\footnotetext{
14.The taxation of labor distorts the leisure-labor decision of households, and reducing this distortion increases aggregate economic efficiency (see, e.g., (Goulder, 1995)).
} 

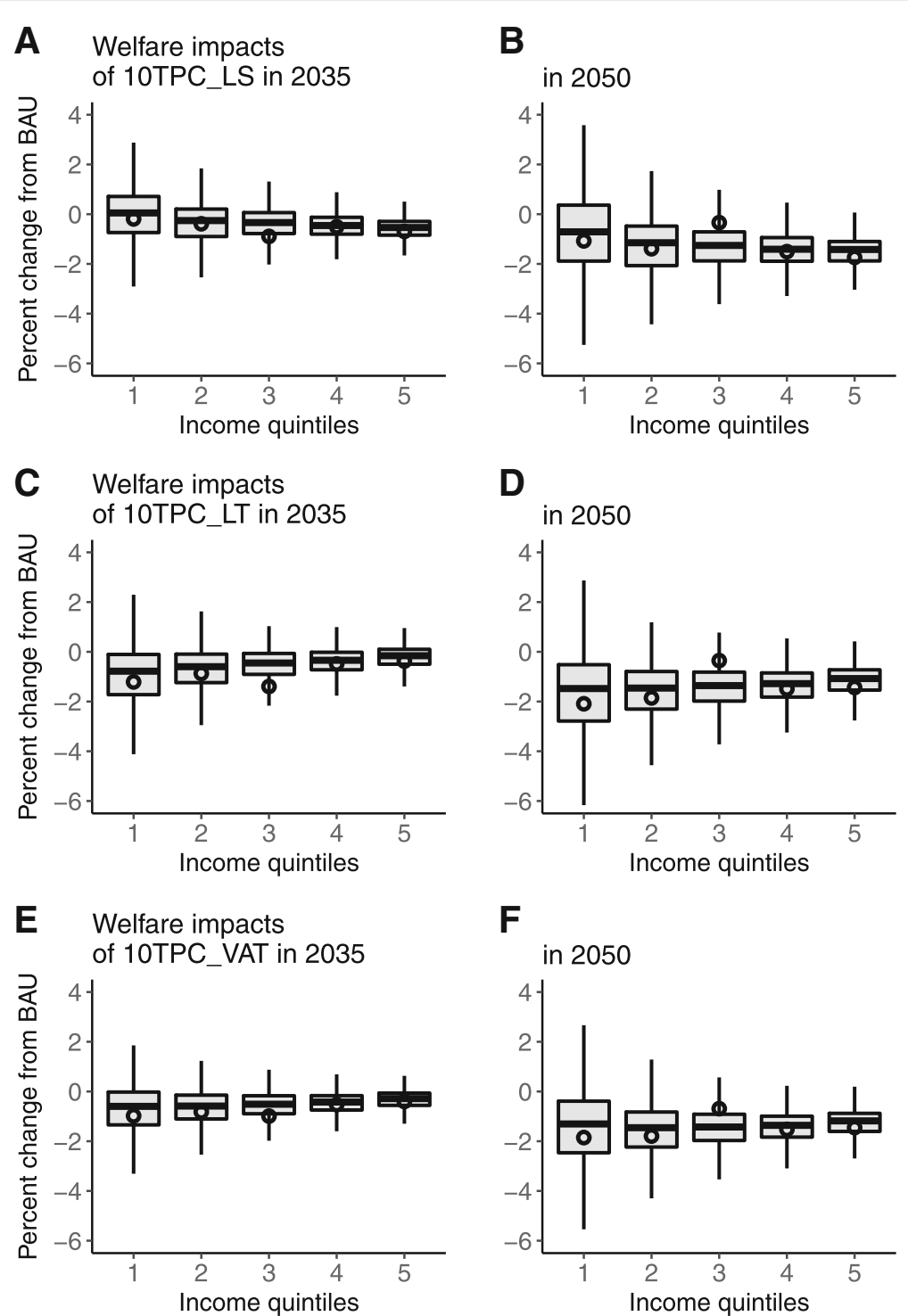

Fig. 3 Distribution of welfare impacts across income quintiles for different revenue recycling schemes (10TPC target) in 2035 (a, c, and e) and 2050 (b, d, and $\mathbf{f}$ )

Table 8 Social welfare for different years and scenarios

\begin{tabular}{lllllll}
\hline \multicolumn{2}{c}{$\begin{array}{l}\text { 2035 } \\
\text { uniform }\end{array}$} & etsDiff & etsUni & $\begin{array}{l}2050 \\
\text { uniform }\end{array}$ & etsDiff & etsUni \\
\hline 15TPC & & & & & & \\
LS & -0.181 & -0.215 & -0.189 & -0.763 & -0.807 & -0.777 \\
LT & -0.567 & -0.572 & -0.600 & -1.133 & -1.157 & -1.157 \\
VAT & -0.530 & -0.535 & -0.559 & -1.105 & -1.129 & -1.127 \\
10TPC & & & & & & \\
LS & -0.370 & -0.480 & -0.406 & -1.348 & -1.564 & -1.439 \\
LT & -0.872 & -1.054 & -0.954 & -1.828 & -2.006 & -1.936 \\
VAT & -0.813 & -0.902 & -0.878 & -1.792 & -1.966 & -1.895 \\
\hline
\end{tabular}

Note: Choices of recycling schemes and carbon tax design that yield the highest social welfare are in bold, and choices that yield the lowest MEl are in italic font additional benefits from more efficient labor supply decisions would also have to be traded off against equity concerns.

Also, the model cannot discern cantonal budgets, and due to different income tax rates in different cantons, in reality, revenue neutrality by canton may require different levels of budget balancing, which may have further impacts on the distribution of overall policy cost. In my modeling, I implicitly assume that such differences in budgets of cantons are compensated by inter-cantonal transfers.

\section{Appendix 1: Additional BAU statistics}

Figures 4 to 6 show the distribution of income (as by the model), share of expenditures liable to VAT reductions 

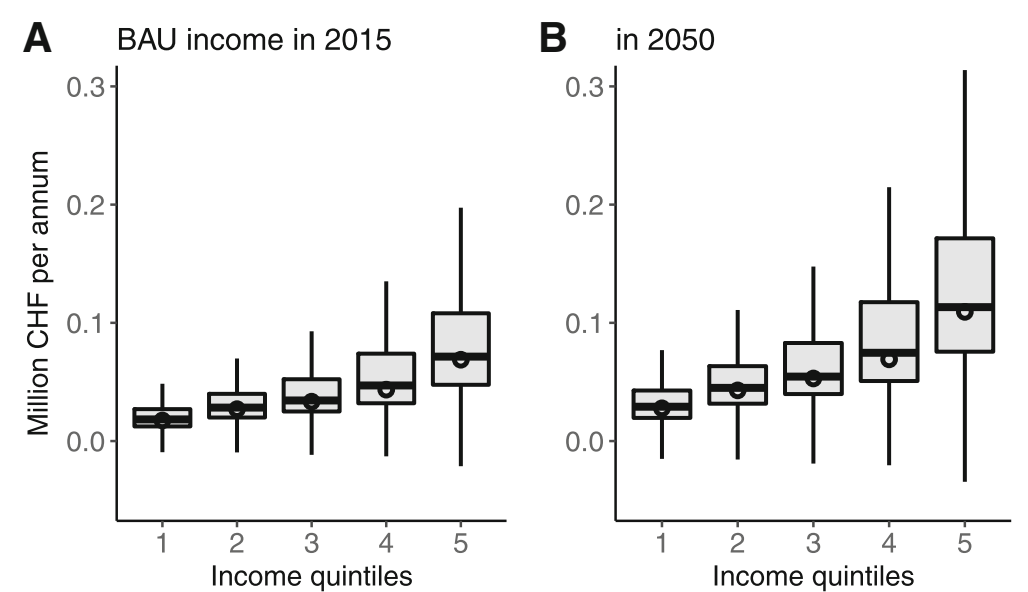

Fig. 4 Distribution of income as measured by the model within and across income quintiles in 2015 (a) and in 2050 (b). Note: Income quintiles are according to allocation by the statistical office. The circles show mean values
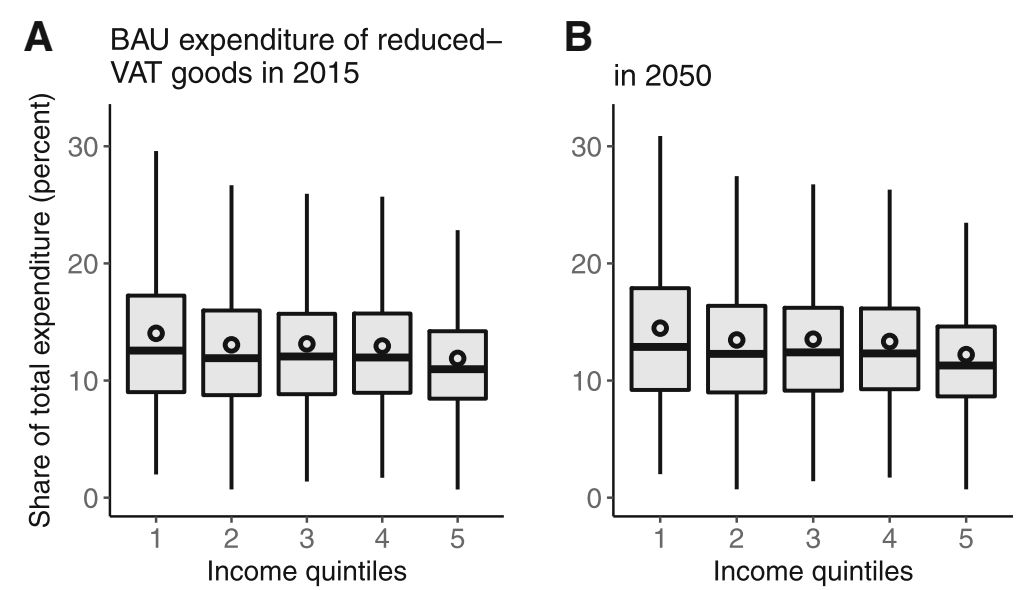

Fig. 5 Distribution of share of expenditures liable to VAT reductions in the VAT-reducing recycling scenarios within and across income quintiles in 2015 (a) and in 2050 (b). Note: Income quintiles are according to allocation by the statistical office. The circles show mean values
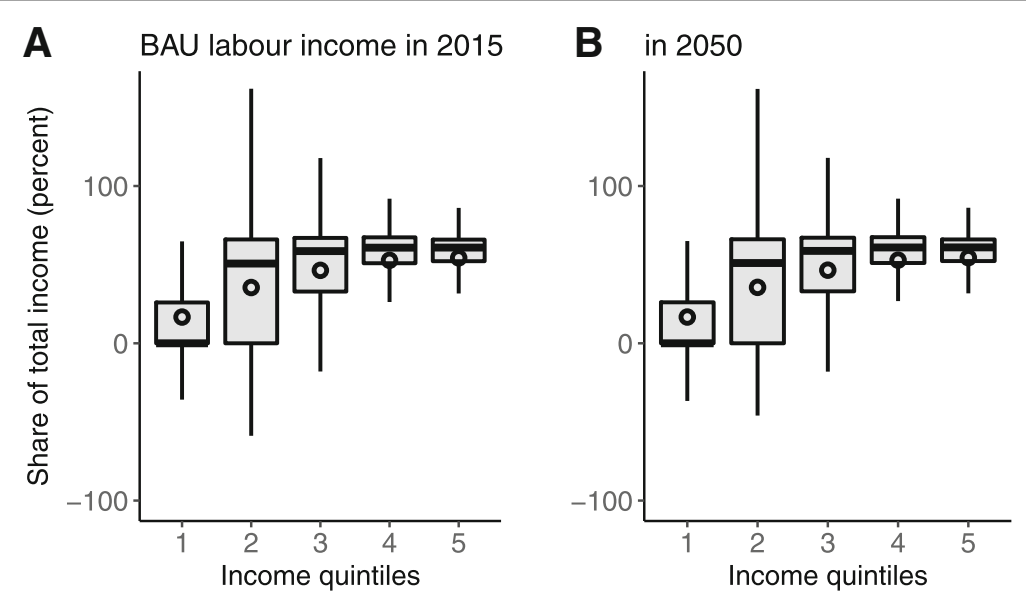

Fig. 6 Distribution of share of labor income in total household income within and across income quintiles in 2015 (a) and in 2050 (b). Note: Income quintiles are according to allocation by the statistical office. The circles show mean values 


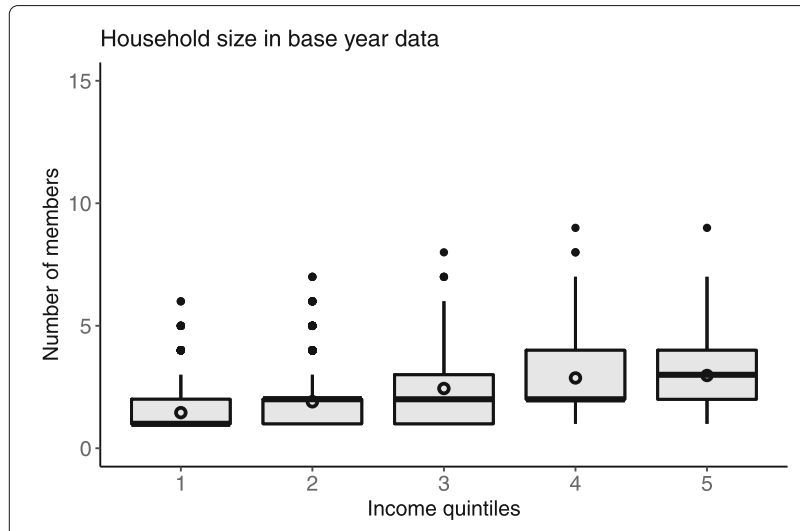

Fig. 7 Distribution of household size within and across income quintiles. Note: Income quintiles are according to allocation by the statistical office. The circles show mean values

in the respective scenarios, and share of labor income in total income within and across income quintiles. Note that in the base year situation, I calibrate the model to 63 households display negative income due to net transfer payments that exceed taxed labor and capital income (their consumption budget is still positive due to dissaving). In the BAU, this number remains 63 and increases to 64 for some policy scenarios. These negative incomes are reflected by the whiskers of the box plots Figs. 4 and 6 reaching below 0 (labor income is always positive, and its share in negative income was reported as negative).

Figure 7 shows household size across income quintiles. It can be seen that households in upper income deciles tend to be larger.

\section{Appendix 2: Sensitivity analysis with respect to inequality aversion}

This section of the Appendix displays results for social welfare if alternative parameters for the inequality aversion are assumed. Table 9 shows the results for the inequality aversion parameter $\varepsilon=0.85$ and Table 10 for $\varepsilon=1.85$.

It should be noted that in the case of $\varepsilon=1.85$, welfare results start to become remarkably sensitive to outcomes for very low-income households. My model predicts negative income for about 65 households (depending on the scenario). Ignoring those households for evaluating the Atkinson index yields the numbers presented in this publication. I feel that I can safely ignore these households as outliers as they constitute a small fraction of the modeled households, and the unexpected behavior of their income is due to unconvincing initial data as far as I can tell (unconvincing here means that I find data points unlikely to represent the situation of real households over a longer period of time).
Table 9 Social welfare for different years and scenarios $(\varepsilon=0.85)$

\begin{tabular}{ccccccc}
\hline \multicolumn{2}{c}{$\begin{array}{l}\text { 2035 } \\
\text { Uniform }\end{array}$} & etsDiff & etsUni & Uniform & etsDiff & etsUni \\
\hline 15TPC & & & & & & \\
LS & $-\mathbf{0 . 1 9 6}$ & -0.197 & -0.202 & -0.768 & -0.795 & -0.779 \\
LT & -0.411 & -0.393 & -0.430 & -0.975 & -0.990 & -0.991 \\
VAT & -0.406 & -0.389 & -0.426 & -0.967 & -0.982 & -0.982 \\
10TPC & & & & & & \\
LS & $-\mathbf{0 . 3 6 4}$ & -0.401 & -0.387 & -1.331 & -1.500 & -1.400 \\
LT & -0.637 & -0.661 & -0.680 & -1.592 & -1.738 & -1.665 \\
VAT & -0.634 & -0.651 & -0.676 & -1.586 & -1.731 & -1.659 \\
\hline
\end{tabular}

Note: Choices of recycling schemes and carbon tax design that yield the highest social welfare are in bold, and choices that yield the lowest social welfare are in italic font

\section{Appendix 3: Model description Computational strategy}

Following Mathiesen (1985) and Rutherford (1995), I formulate the model as a mixed complementarity problem and represent the economic equilibrium through three classes of conditions: zero profit, market clearance, and budget balance. Model formulation is automated through the Mathematical Programming System for General Equilibrium Analysis (MPS/GE) (Rutherford, 1999) in GAMS, and the internally formulated model is solved using the PATH solver (Dirkse and Ferris, 1995). The calibration of the numerical model follows the standard procedure in applied general equilibrium modeling (see, for example, Böhringer et al., 2018 and Harrison et al., 1997).

To overcome dimensionality restrictions, I employ a sequential recalibration algorithm as employed by Rutherford and Tarr (2008). The algorithm decomposes the large-scale market equilibrium problem into two subproblems and iterates until a consistent equilibrium solution is found. The first subproblem solves a representative agent version by replacing the heterogeneous households by a single representative agent (RA). The second subproblem

Table 10 Social welfare for different years and scenarios $(\varepsilon=1.85)$

\begin{tabular}{lllllll}
\hline \multicolumn{2}{l}{$\begin{array}{l}2035 \\
\text { uniform }\end{array}$} & etsDiff & etsUni & $\begin{array}{l}2050 \\
\text { uniform }\end{array}$ & etsDiff & etsUni \\
\hline 15TPC & & & & & & \\
LS & -0.311 & -0.535 & -0.365 & -0.806 & -0.894 & -0.839 \\
LT & -1.337 & -1.562 & -1.474 & -1.786 & -1.813 & -1.850 \\
VAT & -1.097 & -1.294 & -1.193 & -1.679 & -1.711 & -1.736 \\
10TPC & & & & & & \\
LS & -0.838 & -1.878 & -1.094 & -1.617 & -2.021 & -1.890 \\
LT & -2.358 & -8.516 & -2.956 & -3.037 & -3.381 & -3.539 \\
VAT & -1.793 & -2.985 & -2.074 & -2.838 & -3.109 & -3.290 \\
\hline
\end{tabular}

Note: Choices of recycling schemes and carbon tax design that yield the highest social welfare are in bold, and choices that yield the lowest social welfare are in italic font 
solves a partial equilibrium relaxation of the household side by evaluating household demand functions taking equilibrium prices from the first subproblem as given. In a next iteration, the utility function of the RA in the first subproblem is recalibrated to the observed aggregate demands of the second subproblem. Solution of the first and then the second subproblem and recalibration of the first subproblem is iterated until the to subproblems have converged. ${ }^{15}$

\section{Nesting structure of consumption and production}

See Figure 8 and Table 11.

\section{Adjustments between household data and national accounts}

See Table 12.

\section{Algebraic description of the model}

We formulate the model as a system of nonlinear inequalities and characterize the economic equilibrium as a mixed complementary problem (MCP) (Mathiesen, 1985 and Rutherford, 1995) ${ }^{16}$ consisting of two classes of conditions: zero profit and market clearance. Zero-profit conditions exhibit complementarity with respect to activity variables (quantities), and market clearance conditions exhibit complementarity with respect to price variables. We use the $\perp$ operate to

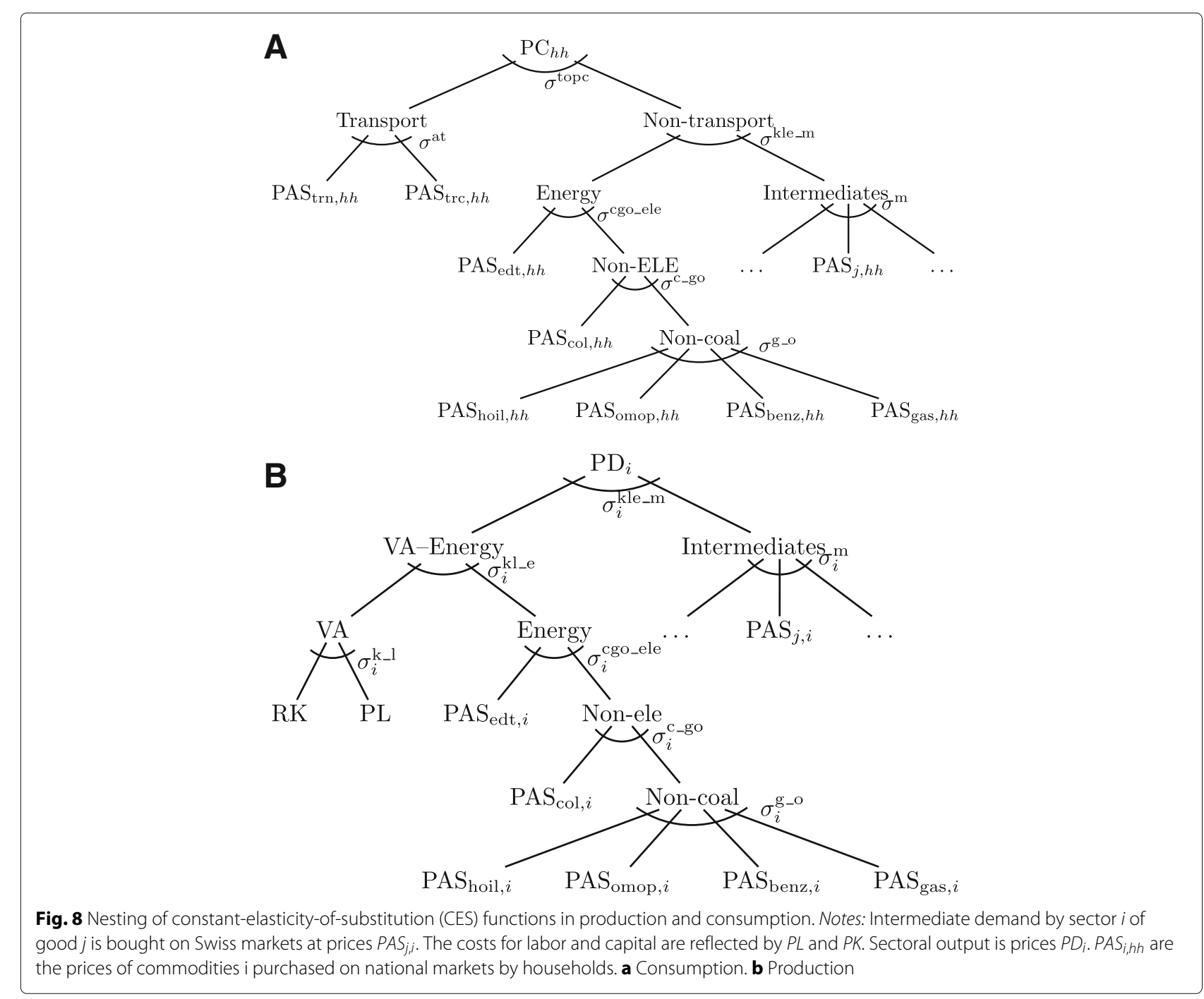

${ }^{15}$ See (Rausch et al., 2011, pp. 3-7) for a more elaborated description of the decomposition algorithm.

${ }^{16}$ A characteristic of many economic models is that they can be cast as a complementary problem. Mathiesen (1985) and Rutherford (1995) have shown that a complementary-based approach is convenient, robust, and efficient. The complementarity format embodies weak inequalities and complementary slackness, relevant features for models that are not integrable and contain bounds on specific variables, for example, activity levels which cannot a priori be assumed to operate at positive intensity. Such features are not easily handled with alternative solution methods. 
Table 11 Elasticities of substitution in utility and production functions and trade

\begin{tabular}{|c|c|c|c|}
\hline & Up to 2020 & 2035 & 2050 \\
\hline \multicolumn{4}{|c|}{ Consumption } \\
\hline$\sigma^{\text {topc }}$ & 0.5 & 0.5 & 0.5 \\
\hline$\sigma^{a t}$ & 0.5 & 0.9 & 1.5 \\
\hline$\sigma^{k l e \_m}$ & 0.5 & 0.9 & 1.5 \\
\hline$\sigma^{\text {cgo_ele }}$ & 0.51 & 0.918 & 1.53 \\
\hline$\sigma^{c \_g o}$ & 0.15 & 0.15 & 0.15 \\
\hline$\sigma^{9 \_} 0$ & 0.75 & 0.75 & 0.75 \\
\hline$\sigma^{m}$ & 0.5 & 0.9 & 1.5 \\
\hline \multicolumn{4}{|c|}{ Production } \\
\hline$\sigma_{i}^{k l e \_m}$ & $0.47-0.5$ & $0.846-0.9$ & $1.41-1.5$ \\
\hline$\left.\sigma_{i}^{k l}\right]^{-}$ & $0.44-0.532$ & $0.85-1.03$ & $1.47-1.77$ \\
\hline$\sigma_{i}^{k-l}$ & $0.48-0.62$ & $0.48-0.62$ & $0.48-0.62$ \\
\hline$\sigma_{i}^{\text {cgo_ele }}$ & 0.51 & 0.918 & 1.53 \\
\hline$\sigma_{i}^{c_{-} g o}$ & 0.15 & 0.15 & 0.15 \\
\hline$\sigma_{i}^{g \_o}$ & 0.75 & 0.75 & 0.75 \\
\hline$\sigma_{i}^{m}$ & 0.25 & 0.45 & 0.75 \\
\hline \multicolumn{4}{|l|}{ Trade } \\
\hline$\sigma_{i}^{A}$ & $0.5-2$ & $0.5-2$ & $0.5-2$ \\
\hline$\sigma_{i}^{T}$ & $0.4-2$ & $0.4-2$ & $0.4-2$ \\
\hline
\end{tabular}

indicate complementarity between equilibrium conditions and variables. Model variables and parameters are defined in Tables 13, 14, and 15. We formulate the problem in GAMS and use the mathematical programming system MPSGE (Rutherford, 1999) and the PATH solver (Dirkse and Ferris, 1995) to solve for non-negative prices and quantities.

\section{Zero-profit conditions}

The zero-profit conditions for activities listed in Table 14 are given in Eqs. (1)-(18) on the next page. ${ }^{17}$ The complementarity program ensures that, at a numerical solution, activities either make zero economic profits or have bigger unit costs than revenues and are thus not active.

Equations (1)-(3) include the activities that transform market goods (priced at $P S_{s t, c}$ and $P A T S_{i, c}$ ) into (aggregate) household welfare (priced at $P W_{c}$ ). Equation 2 shows how cost of generating commodities $g$ relate to their sale prices on the domestic market $P D_{g}$ and on the world market PFX. Differentiating their output between supply to the domestic and supply to export market, the different industries face the constant-elasticity-of-transformation functions

$$
r_{g}^{Y X}:=\left[\theta_{D, g}^{Y X}\left(P D_{g}\right)^{1+\sigma_{g}^{T}}+\left(1-\theta_{D, g}^{Y X}\right)(P F X)^{1+\sigma_{g}^{T}}\right]^{\frac{1}{1+\sigma_{g}^{T}}}
$$

This differentiation on the output side is only made for traded commodities and the local commodities "household consumption," "government consumption," and "investment demand" $(g \in\{\mathrm{hh}$, inv, govt $\})$ are not exported $\left(\theta_{g}^{D}=1\right)$.

The unit cost function in (3) for the aggregate consumption basket is ${ }^{18}$

$$
c_{c}^{Y}:=\left[\theta_{t a, c}^{t o p c}\left(c_{c}^{t a}\right)^{0.5}+\left(1-\theta_{t a, c}^{t o p c}\right)\left(c_{c}^{k l e \_m}\right)^{0.5}\right]^{2} \quad \forall c \in C,
$$

where

\footnotetext{
${ }^{17}$ In the equations, $c^{A C T}$ denote the cost function of activities ACT and $r^{A C T}$ their revenue functions.

${ }^{18}$ This model description adheres to the following conventions of notation. $\theta_{S I, o i}^{N I}$ denotes the value share of good or subnest $S I$ in nest $N I$ of a nested cost function at benchmark prices. Thus, shares of all goods and subnests in any given nest add up to 1 . Benchmark levels of price variables $P$ are denoted by parameters $\bar{p}$.
} 


$$
\begin{aligned}
& c_{c}^{t a}:=\left[\sum_{j \in\{\mathrm{atp}, \mathrm{trc}\}} \theta_{j, c}^{t a}\left(\frac{\operatorname{PATS}_{j, c}}{\overline{\text { pats }_{j, c}}}\right)^{1-\sigma_{c}^{t a}}\right]^{\frac{1}{1-\sigma_{c}^{t a}}} \\
& c_{c}^{k l e \_m}:=\left[\theta_{m, c}^{k l e \_m}\left(c_{c}^{m}\right)^{1-\sigma_{c}^{k l e \_m}}+\left(1-\theta_{m, c}^{k l e \_m}\right)\left(c_{c}^{c g o \_ \text {ele }}\right)^{1-\sigma_{c}^{k l e \_m}}\right]^{\frac{1}{1-\sigma_{c}^{k l e \_m}}} \\
& c_{c}^{m}:=\left[\sum_{j \in m a t} \theta_{j, c}^{m}\left(\frac{\operatorname{PATS}_{j, c}}{\overline{\text { pats }_{j, c}}}\right)^{1-\sigma_{c}^{m}}\right]^{\frac{1}{1-\sigma_{c}^{m}}} \\
& c_{c}^{c g o \_e l e}:=\left[\theta_{\mathrm{edt}, c}^{c g o \_e l e}\left(\frac{P A T S_{\mathrm{edt}, c}}{\overline{p a t S_{\mathrm{edt}, c}}}\right)^{1-\sigma_{c}^{c g o \_e l e}}+\left(1-\theta_{\mathrm{edt}, c}^{c g o \_e l e}\right)\left(c_{c}^{c \_g o}\right)^{1-\sigma_{c}^{c g o} \_l e}\right]^{\frac{1}{1-\sigma_{c}^{c g} \_ \text {ele }}} \\
& c_{c}^{c_{-} g o}:=\left[\theta_{\mathrm{coa}, c}^{c-g o}\left(\frac{\operatorname{PATS}_{\mathrm{coa}, c}}{\overline{p a t s_{\mathrm{coa}, c}}}\right)^{1-\sigma_{c}^{c-g o}}+\left(1-\theta_{\mathrm{coa}, c}^{c_{-} g o}\right)\left(c_{c}^{g_{c} o}\right)^{1-\sigma_{c}^{c_{c} g o}}\right]^{\frac{1}{1-\sigma_{c}^{c-g o}}} \\
& c_{c}^{g_{c} o}:=\left[\sum_{j \in\{\text { hoil,omop,gas,benz }\}} \theta_{j, c}^{g_{-} o}\left(\frac{\operatorname{PATS}_{j, c}}{\overline{\text { pats }_{j, c}}}\right)^{1-\sigma_{c}^{g_{-} o}}\right]^{\frac{1}{1-\sigma_{c}^{g_{c} o}}} .
\end{aligned}
$$

$$
\begin{aligned}
& P D_{c} \geq P W_{c} \quad \perp W_{c} \geq 0 \quad \forall c \\
& P_{g} \geq r_{g}^{Y X}\left(P D_{g}, P F X\right) \quad \perp Y X_{g} \geq 0 \quad \forall g \\
& c_{c}^{Y}\left(P A T S_{i, c}\right) \geq P_{c} \\
& \perp \quad Y_{c} \geq 0 \quad \forall c \in C \\
& c_{i, g}^{A S}\left(P A_{i}, P E D T, P C O 2^{(E T S)}, P M O T, R E C^{\mathrm{VAT}}\right) \\
& \begin{array}{ll}
\geq \text { PATS }_{i, g} & \perp A S_{i, g} \geq 0 \quad \forall i, g
\end{array} \\
& c_{i}^{A}\left(P D_{i}, P M_{i}\right)
\end{aligned}
$$

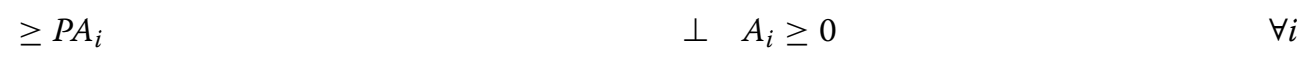

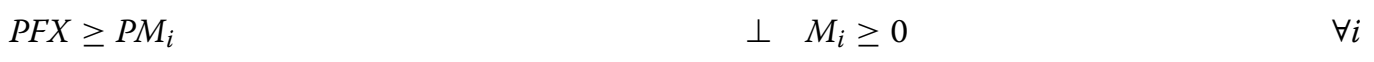

$$
\begin{aligned}
& c_{g}^{Y}\left(\text { PFD }_{f, g}, P A T S_{i, g}\right) \\
& \geq P_{g} \quad \perp Y_{g} \geq 0 \\
& P L \geq P F D_{\mathrm{lab}, i}\left(1-R E C^{W E T S}\right) \\
& \perp \quad L D_{i} \geq 0 \quad \forall i \in \text { ets } \\
& P L \geq P F D_{\mathrm{lab}, i}\left(1-R E C^{W}\right) \quad \perp L D_{i} \geq 0 \\
& \forall i \in I \backslash \text { ets } \\
& P L S_{c} \geq P L\left(1-\frac{R E C^{\mathrm{LT}}}{1+r t f h h_{\mathrm{lab}, \mathrm{hh}}}\right) \quad \perp L S_{c} \geq 0 \quad \forall c \\
& \forall g \in G \backslash(C \cup \text { ele })
\end{aligned}
$$




$$
\begin{aligned}
& R K \geq P F D_{\text {cap }, i} \\
& \perp K D_{i} \geq 0 \quad \forall i \\
& R K S_{c} \geq R K \\
& \perp K S_{c} \geq 0 \quad \forall c \\
& P F X \geq R K \quad \perp K M \geq 0 \\
& R K \geq P F X \quad \perp K X \geq 0 \\
& c_{\text {tec }}^{E T E C}\left(P A T E_{i, t e c}, R K E_{\text {tec }}, P F D_{\text {lab,ele }}\right) \\
& \begin{array}{lll}
\geq P_{\text {ele }} & \perp E T E C_{\text {tec }} \geq 0 \quad \forall t e c
\end{array} \\
& c_{i, t e c}^{A S E}\left(P A_{i}, P E D T, P C O 2^{E T S}, P M O T, P F X\right) \\
& \geq P A T E_{i, t e c} \\
& R K E S_{t e c, c} \geq R K E_{t e c} \\
& \perp A S E_{i, t e c} \geq 0 \quad \forall i, \text { tec } \\
& \perp K E S_{\text {tec, },} \geq 0 \quad \forall t e c, c \\
& P I N C_{c} \geq \theta_{L, c}^{I N C} P L S_{c} \\
& +\theta_{K, c}^{I N C} R K S_{c} \\
& +\theta_{K E, t e c, c}^{I N C} R K E S_{t e c, c} \\
& +\theta_{T, c}^{I N C} P_{c} \quad \perp \quad N C M_{c} \geq 0
\end{aligned}
$$

The commodity prices $P A T S_{i, g}$ faced by consumers are local market prices $P A_{i}$ plus taxes. Taxes include ad valorem tax rates according to the SAM $\left(r t v a_{i, g}\right.$ and $\left.r t o t h_{i, g}\right)$ on the one hand and mineral oil taxes $M O T_{i, g}, \mathrm{CO}_{2}$ taxes $P C O 2$ and energy taxes $P E D T$ on physical quantities on the other. Thus, cost function $c^{A S}$ in Eq. 4 is

$$
\begin{array}{rlrl}
c_{i, g}^{A S}:= & \frac{1+r t v a_{i, g}+r \text { toth }_{i, g}-R E C^{\mathrm{VAT}}}{1+r t v a_{i, g}+r t o t h_{i, g}+r t m o t_{i, g}} P A_{i} & \\
& +\phi_{i, g}^{C O 2} \text { mult }_{i} \cdot P C O 2+\phi_{i, g}^{E D T} P E D T+\phi_{i, g}^{M O T} P M O T & & \\
c_{i, g}^{A S}:= & \frac{1+r t v a_{i, g}+r \text { toth }_{i, g}-R E C^{\mathrm{VAT}}}{1+r t v a_{i, g}+r t o t h_{i, g}+r t m o t_{i, g}} P A_{i} & \\
& +\phi_{i, g}^{C O 2} P C O 2^{E T S}+\phi_{i, g}^{E D T} P E D T+\phi_{i, g}^{M O T} P M O T & \forall i \in I, g \in \text { ets },
\end{array}
$$

where mult $_{i} \cdot \mathrm{PCO}_{2}$ and $P C O 2{ }^{E T S}$ are the costs of emitting $\mathrm{CO}_{2}$ outside and inside the ETS in $\mathrm{CHF} / \mathrm{tCO} 2$ and PEDT is the energy tax in CHF/PJ. $\phi_{i, g}^{C O 2}$ is the carbon content of commodity $i$ purchased by agent $g$ in $\mathrm{tCO}_{2} / \mathrm{CHF}$ and $\phi_{i, g}^{E D T}$ is the energy content in PJ/MCHF. $\phi_{i, g}^{M O T}$ is the amount of mineral oil tax due per value of $A S$.

The goods $i$ on domestic markets are composed of domestically produced varieties and imported varieties of goods $i$. The trade-off between the two is modeled as a CES production function according to the Armington assumption and the domestic market price is determined according to the cost function

$$
c_{i}^{A}:=\left[\theta_{D, i}^{A}\left(P D_{i}\right)^{1-\sigma^{A}}+\left(1-\theta_{D, i}^{A}\right)(P F X)^{1-\sigma^{A}}\right]^{\frac{1}{1-\sigma^{A}}}
$$

in Eq. 5. (6) describes how the price $P M_{i}$ of imports depends on the exchange rate $P F X$.

Domestic production of industrial output in Eq. 7 faces the cost function 


$$
c_{g}^{Y}:=\left[\theta_{k l \_e g}^{k l e \_m}\left(c_{g}^{k l \_e}\right)^{1-\sigma_{g}^{k l e \_m}}+\left(1-\theta_{k l \_e, g}^{k l e \_m}\right)\left(c_{g}^{m}\right)^{1-\sigma_{g}^{k l e \_m}}\right]^{\frac{1}{1-\sigma_{g}^{k l e \_m}}}
$$

where

$$
\begin{aligned}
& c_{g}^{m}:=\left[\sum_{j \in m a t} \theta_{j, g}^{m}\left(\frac{\text { PATS }_{j, g}}{\overline{\text { pats }_{j, g}}}\right)^{1-\sigma_{g}^{m}}\right]^{\frac{1}{1-\sigma_{g}^{m}}} \\
& c_{g}^{k l \_e}:=\left[\theta_{k_{-}, g}^{k l, e}\left(c_{g}^{k \_l}\right)^{1-\sigma_{g}^{k l \_} e}+\left(1-\theta_{k \_-g}^{k l \_e}\right)\left(c_{g}^{c g o \_e l e}\right)^{1-\sigma_{g}^{k l \_e}}\right]^{\frac{1}{1-\sigma_{g}^{k l \_} e}} \\
& c_{g}^{k_{-} l}:=\left[\sum_{f \in F} \theta_{f, g}^{k_{-} l}\left(\frac{\left(1+r t f_{f, g}\right) P F D_{f, g}}{\overline{p f d_{f, g}}}\right)^{1-\sigma_{g}^{k-l}}\right]^{\frac{1}{1-\sigma_{g}^{k-l}}}
\end{aligned}
$$

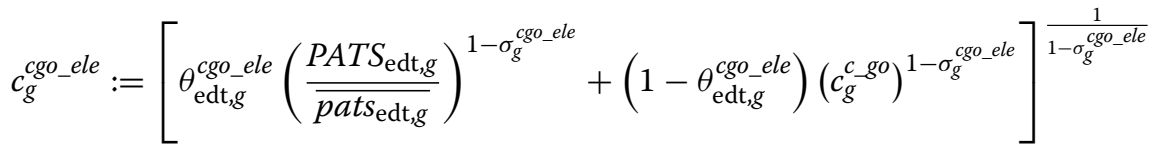

$$
\begin{aligned}
& c_{g}^{c_{-} g o}:=\left[\theta_{\mathrm{coa}, g}^{c_{-} g o}\left(\frac{P A T S_{\mathrm{coa}, g}}{\overline{p a t s_{\mathrm{coa}, g}}}\right)^{1-\sigma_{g}^{c_{g} g o}}+\left(1-\theta_{\mathrm{coa}, g}^{c_{-} g o}\right)\left(c_{g}^{g_{-} o}\right)^{1-\sigma_{g}^{c_{-} g o}}\right]^{\frac{1}{1-\sigma_{g}^{c_{g} g o}}} \\
& c_{g}^{g_{-} o}:=\left[\sum_{j \in\{\text { hoil,omop,gas,benz }\}} \theta_{j, g}^{g_{-} o}\left(\frac{P A T S_{j, g}}{\overline{p a t s_{j, g}}}\right)^{1-\sigma_{g}^{g_{-} o}}\right]^{\frac{1}{1-\sigma_{g}^{g_{-} o}}} .
\end{aligned}
$$

Besides intermediate inputs prices at $P A T S_{i, g}$ production sectors require labor and capital services priced at $P F D_{f, i}$. Equations 8-(12) describe how these prices are derived from net wages $P L S_{c}$ and net capital rents $R K_{c}$ received by consumers. General purpose capital services can be traded across international borders and thus, capital rents are determined by the exchange rate $P F X$ as in (13) and (14).

Electricity, finally, is produced using different technologies tec. Their cost function in Eq. 15 is given by

$$
\begin{aligned}
& c_{\text {tec }}^{E T E C}:= {\left[\theta_{K, t e c}^{E L E}\left(R K E_{\text {tec }}\right)^{1-\sigma_{\text {tec }}^{E L E}}+\left(1-\theta_{K, t e c}^{E L E}\right)\left(c_{\text {tec }}^{O M}\right.\right.} \\
& \text { where } \\
& c_{\text {tec }}^{O M}:=\theta_{\text {lab,tec }}^{O M} P F D_{\text {lab,ele }}+\sum_{i} \theta_{i, t e c}^{O M} P A T E_{i, t e c}
\end{aligned}
$$

Their intermediate inputs are priced at $P A T E_{i, t e c}$ and this includes market price $P A_{i}$ plus taxes as given by Eq. 16 and

$$
\begin{aligned}
& c_{i, t e c}^{A S E}:=\frac{1+r t v a_{i, t e c}^{e}+r t o t h_{i, t e c}^{e}}{1+r t v a_{i, t e c}^{e}+r t o t h_{i, t e c}^{e}+r \text { tmot }_{i, t e c}} P A_{i} \\
& +\phi_{i, t e c}^{C O 2} P C O 2^{E T S}+\phi_{i, t e c}^{E D T} P E D T+\phi_{i, t e c}^{M O T} P M O T \quad \forall i \in I, \text { tec } \in T \backslash\{\text { fos }\} \text {, }
\end{aligned}
$$




$$
\begin{array}{rlr}
c_{i, \mathrm{fos}}^{A S E} & :=\frac{1+r t v a_{i, \mathrm{fos}}^{e}+r t o t h_{i, \mathrm{fos}}^{e}}{1+r t v a_{i, \mathrm{fos}}^{e}+r t o t h_{i, \mathrm{fos}}^{e}+r t m o t^{e}{ }_{i, \mathrm{fos}}} P A_{i} & \\
& +\phi_{i, \mathrm{fos}}^{\operatorname{CO} 2} \frac{P C O 2^{E T S}+P F X \cdot p^{C O 2}}{2}+\phi_{i, \mathrm{fos}}^{E D T} P E D T+\phi_{i, \mathrm{fos}}^{M O T} P M O T & \forall i \in I .
\end{array}
$$

The specialized capital services that the power generation technologies require are priced at $R K E_{t e c}$ which relates to net capital rents $R K E S_{t e c, c}$ earned by households as in (17).

A price index of overall net income by consumers is given in Eq. 18.

\section{Market balance equations}

$$
\begin{aligned}
& W_{c} \operatorname{vom}_{c} \geq \frac{R A_{c}}{P W_{c}} \\
& \perp \quad P W_{c} \geq 0 \\
& \forall c \\
& Y X_{c} \geq W_{c} \\
& \perp \quad P D_{c} \geq 0 \\
& \forall c \\
& Y X_{i} \frac{\partial c_{i}^{X Y}}{\partial P D_{i}} \geq A_{i} \frac{\partial c_{i}^{A}}{\partial P D_{i}} \\
& \perp \quad P D_{i} \geq 0 \\
& \forall i \\
& Y X_{\text {govt }} \text { vom }_{\text {govt }} \geq \frac{G O V T}{P D_{\text {govt }}} \\
& \perp \quad P D_{\text {govt }} \geq 0 \\
& Y X_{\mathrm{inv}} \operatorname{vom}_{\mathrm{inv}} \geq \sum_{c} v i d_{c} \\
& \perp \quad P D_{\text {inv }} \geq 0
\end{aligned}
$$

$$
\operatorname{vex}_{i} Y X_{i} \frac{\partial r_{i}^{X Y}}{\partial P F X} p_{i}^{T R D}+K X
$$$$
\geq \operatorname{vim}_{i} M_{i} p_{i}^{T R D}+K M+v b
$$$$
+\operatorname{vafm}_{i, \mathrm{fos}}^{e} A S E_{i, \text { fos }} \frac{\partial c_{i, \mathrm{fos}}^{A S E}}{\partial P F X}
$$$$
\perp \quad P F X \geq 0
$$

$$
Y_{g} \geq Y X_{g}
$$

$\perp \quad P_{g} \geq 0$

$$
\forall g \in G \backslash \text { ele }
$$

$$
\sum_{t e c} v o m_{t e c}^{e} E T E C_{t e c} \geq v o m_{\text {ele }} Y X_{\text {ele }}
$$

$\perp \quad P_{\text {ele }} \geq 0$

$$
\begin{aligned}
& A S_{i, g} \geq Y_{g} \frac{\partial c_{g}^{Y}}{\partial P A T S_{i, g}} \\
& \operatorname{vam}_{i} A_{i} \geq \sum_{g \in G \backslash e l e} A S_{i, g} \\
& \cdot\left(\operatorname{vafm}_{i, g}-\operatorname{vtax}_{i, g}\right) \\
&+\sum_{t e c} A S E_{i, t e c} \\
& \cdot\left(v_{\text {afm }}^{e}{ }_{i, t e c}^{e}-v \text { tax }_{i, t e c}^{e}\right)
\end{aligned}
$$$$
\perp \quad \text { PATS }_{i, g} \geq 0
$$$$
\forall i, g
$$

$\perp \quad P A_{i} \geq 0$

$$
\text { dedt } \cdot M U^{E} \geq \sum_{g \in G \backslash \text { ele }} A S_{\text {edt }, g} \text { ene } e_{\text {edt }, g}
$$




$$
\begin{aligned}
& +\sum_{t e c} A S E_{\mathrm{edt}, t e c} e n e_{\mathrm{edt}, t e c}^{e} \\
& \perp \quad P E D T \geq 0 \\
& \text { etscap } \geq \sum_{e, g \in e t s} c o 2_{e, g} A S_{e, g} \\
& +\sum_{e, t e c} c o 2_{e, t e c}^{e} A S E_{e, t e c} \\
& -\sum_{e} \frac{c o 2_{e, \text { fos }}^{e}}{2} A S E_{e, \text { fos }} \quad \perp \quad P C O 2^{E T S} \geq 0 \\
& \text { cemi } \cdot \text { EMICARB } \geq \sum_{e, g \in \text { nets }} c o 2_{e, g} A S_{e, g} \quad \perp \quad P C O 2 \geq 0 \\
& M_{i} \geq A_{i} \frac{\partial c_{i}^{A}}{\partial P M_{i}} \\
& L D_{i} \geq Y_{i} \frac{\partial c_{i}^{Y}}{\partial P F D_{\mathrm{lab}, i}} \\
& \perp \quad P M_{i} \geq 0 \\
& \perp \quad P F D_{\mathrm{lab}, i} \geq 0 \\
& \forall i \in I \backslash \text { ele } \\
& E T E C_{\text {tec }} \frac{\partial c_{\text {tec }}^{E T E C}}{P F D_{\text {lab,ele }}} \\
& \perp \quad P F D_{\text {lab,ele }} \geq 0 \\
& K D_{i} \geq Y_{i} \frac{\partial c_{i}^{Y}}{\partial P F D_{\text {cap }, i}} \\
& A S E_{i, t e c} \geq E T E C_{t e c} \frac{\partial c^{E T E C}}{\partial P A T E_{i, t e c}} \\
& \sum_{c} L S_{c} \text { evom }_{\mathrm{lab}, c} \geq \sum_{i} L D_{i} v f m_{\mathrm{lab}, i} \\
& 1 \geq L S_{c} \\
& \sum_{c} K S_{c} \text { evom }_{\mathrm{cap}, c} \geq \sum_{i} K D_{i} v f m_{\mathrm{cap}, i} \\
& 1 \geq K S_{c} \\
& \perp \quad P F D_{\text {cap }, i} \geq 0 \\
& \forall i \in I \backslash \text { ele } \\
& \perp \quad P A T E_{i, t e c} \geq 0 \\
& \forall i, \text { tec } \\
& \perp \quad P L \geq 0 \\
& \perp \quad P L S_{c} \geq 0 \\
& \perp \quad R K \geq 0 \\
& \perp \quad R K S_{c} \geq 0 \\
& \sum_{c} K E S_{c} e v o m_{t e c, c}^{e} \geq \quad v f m_{\text {cap }, t e c}^{e} \\
& E T E C_{t e c} \frac{\partial c_{t e c}^{E T E C}}{\partial R K E_{t e c}} \\
& 1 \geq K S E_{t e c, c} \\
& \perp \quad R K E_{t e c} \geq 0 \\
& \forall \text { tec } \\
& \perp \quad R K E S_{t e c, c} \geq 0 \quad \forall t e c, c \\
& 1 \geq N C M_{c} \\
& \perp \quad \operatorname{PINC}_{c} \geq 0 \\
& \forall c \\
& Q M O T \geq \sum_{i, g} A S_{i, g} v t m o_{i, g} \\
& +\sum_{i, t e c} A S E_{i, t e c} v t m o_{i, t e c}^{e} \\
& \perp \quad P M O T \geq 0
\end{aligned}
$$


Income balance equations

$$
\begin{aligned}
& R A_{\mathrm{hh}} \geq v i n c_{\mathrm{hh}} P I N C_{\mathrm{hh}}-v i d_{\mathrm{hh}} P W_{\mathrm{hh}}+R E C^{\mathrm{LS}} P F X \\
& - \text { REINVEST } \cdot \text { PFX } \quad \perp \quad R A_{\mathrm{hh}} \geq 0 \\
& R A_{\text {reinvest }} \geq v i n c_{\text {reinvest }} P I N C_{\text {reinvest }}-v i d_{\text {reinvest }} P D_{\text {inv }} \\
& + \text { REINVEST } \cdot \text { PFX } \\
& \perp \quad R A_{\text {reinvest }} \geq 0 \\
& G O V T \geq\left(P W_{\mathrm{hh}}-P D_{\mathrm{inv}}\right) v i d_{\mathrm{hh}} \\
& -P W_{\mathrm{hh}}\left(\text { tcorr }_{\mathrm{hh}}+\operatorname{trf} f_{\mathrm{hh}}\right)-P F X\left(R E C^{\mathrm{LS}}+v b\right) \\
& +P E D T \cdot \operatorname{dedt} \cdot M U^{E}+P C O 2^{E T S} \cdot \text { etscap } \\
& + \text { PCO2 } \cdot \sum_{e, g \in \text { nets }} A S_{i, g} c o 2_{e, g} \cdot \text { mult }_{i} \\
& +R E V T \cdot \operatorname{vinc}_{\mathrm{hh}} \cdot N C M_{\mathrm{hh}} \\
& +R K E_{t e c} \cdot K E S_{\text {tec,hh }} \cdot \text { evom tec,hh }^{e} \cdot \text { mrtinctec }_{\text {tec,hh }} \\
& +R K \cdot K S_{\mathrm{hh}} \cdot \text { evom }_{\mathrm{cap}, \mathrm{hh}} \cdot \operatorname{mrtincf}_{\mathrm{cap}, \mathrm{hh}} \\
& +P L S_{\mathrm{hh}} \cdot L S_{\mathrm{hh}}\left(\text { evom }_{\mathrm{lab}, \mathrm{hh}}-m v t f i n c_{\mathrm{lab}, \mathrm{hh}}-v t f_{\mathrm{lab}, \mathrm{hh}}\right) \cdot m r t l i n c_{\mathrm{hh}}^{\text {net }} \\
& +P L \cdot L S_{\mathrm{hh}} \text { evom }_{\mathrm{lab}, \mathrm{hh}}\left(r t f h h_{\mathrm{lab}, \mathrm{hh}}-R E C^{\mathrm{LT}}\right) \\
& -R E C^{W E T S} \sum_{i \in \text { ets }} P F D_{\mathrm{lab}, i} L D_{i} v f m_{\mathrm{lab}, i}-R E C^{W} \sum_{i \in \text { nets }} P F D_{\mathrm{lab}, i} L D_{i} v f m_{\mathrm{lab}, i} \\
& +\sum_{i} P M_{i} A_{i} \operatorname{vim}_{i} \cdot r t i_{i}+P F X \sum_{i} Y X_{i} \frac{\partial r_{i}^{Y X}}{\partial P F X} \text { vex }_{i} \cdot \text { rtavrow }_{i} \\
& +\sum_{i, t e c} A S E_{i, t e c} P A_{i}\left(v a f m_{i, t e c}^{e}-v t a x_{i, t e c}^{e}\right)\left(\operatorname{rtav}_{i, t e c}^{e}-R E C^{\mathrm{VAT}}\right) \\
& +\sum_{i, g} A S_{i, g} P A_{i}\left(\operatorname{vafm}_{i, g}-\operatorname{vtax}_{i, g}\right)\left(\operatorname{rtav}_{i, g}-R E C^{\mathrm{VAT}}\right) \\
& +P F D_{\text {lab,ele }} \sum_{\text {tec }} E T E C_{\text {tec }} \frac{\partial c_{t e c}^{E T E C}}{\partial P F D_{\text {lab,ele }}} v f m_{\text {lab,tec }}^{e} r t f_{\text {lab,tec }}^{e} \\
& +\sum_{t e c} R K E_{t e c} E T E C_{t e c} \frac{\partial c_{t e c}^{E T E C}}{\partial R K E_{t e c}} v f m_{\text {cap }, t e c}^{e} r t f_{\text {cap }, t e c}^{e} \\
& +\sum_{f, i \in I \backslash e l e} \operatorname{PFD}_{f, i} Y_{i} \frac{\partial c_{i}^{Y}}{\partial P F D_{f, i}} \mathrm{vfm}_{f, i} r t f_{f, i} \\
& +P M O T \cdot Q M O T \\
& \perp \text { GOVT } \geq 0 .
\end{aligned}
$$

\section{Constraints for auxiliary variables}

In order to realistically represent the options in Swiss climate and energy policy, the model contains additional auxiliary variables (see Table 14) and their corresponding constraints.

In several constraints for auxiliary variables, price levels have to be targeted. Some of the price levels are set in relation to the consumer price index PINDEX determined by

$$
\text { PINDEX } \geq P_{\mathrm{hh}}
$$


Table 12 Income and expenditure categories aggregated from household survey data compared with national accounts (numbers are in million Swiss Francs)

\begin{tabular}{|c|c|c|c|c|}
\hline HABE & Model & HABE & Model & Adjustment factor \\
\hline Food and non-alcoholic beverages & C01 & 26,000 & 30,894 & 1.19 \\
\hline Alcoholic beverages and tobacco & $\mathrm{CO} 2$ & 4172 & 9926 & 2.38 \\
\hline Clothing and footwear & $\mathrm{CO3}$ & 9240 & 11,312 & 1.22 \\
\hline Housing and energy & CO4 & 58,586 & 72,790 & 1.24 \\
\hline Furniture, equipment, and maintenance & C05 & 11,218 & 13,651 & 1.22 \\
\hline Health & C06 & 10,380 & 43,510 & 4.19 \\
\hline Transport & $\mathrm{CO}$ & 29,156 & 30,075 & 1.03 \\
\hline Communications & $\mathrm{C08}$ & 6990 & 7771 & 1.11 \\
\hline Recreation and culture & C09 & 25,555 & 21,482 & 0.84 \\
\hline Restaurants and hotels & $\mathrm{C} 11$ & 21,379 & 21,718 & 1.02 \\
\hline Other goods and services & C1012 & 11,198 & 34,980 & 3.12 \\
\hline Social security contributions & Tax on wages & 35,017 & 75,989 & 2.17 \\
\hline Health insurance: basic coverage & Transfers & 19,699 & 18,186 & 0.92 \\
\hline Taxes & Tax on income & 43,585 & 62,558 & 1.44 \\
\hline Health insurance: additional coverage & Transfers & 5071 & 4681 & 0.92 \\
\hline Other insurance & Transfers & 7500 & 6924 & 0.92 \\
\hline Fees & Transfers & 2855 & 2636 & 0.92 \\
\hline Donations and gifts & Transfers & 6985 & 6448 & 0.92 \\
\hline Income from employment & Labor & 276,119 & 274,393 & 0.99 \\
\hline Income from property and letting & Capital & 31,127 & 111,228 & 3.57 \\
\hline Pensions and social benefits & Transfers & 69,626 & 64,276 & 0.92 \\
\hline Transfers from other households & Transfers & 5541 & 5115 & 0.92 \\
\hline Intermittent income & Transfers & 16,686 & 15,404 & 0.92 \\
\hline Pensions from AHV/IV & Transfers & 31,682 & 29,248 & 0.92 \\
\hline Pensions from pension funds & Transfers & 24,643 & 22,750 & 0.92 \\
\hline Benefits and daily allowances & Transfers & 13,301 & 12,279 & 0.92 \\
\hline Residual & Savings & 134,137 & 59,160 & 0.44 \\
\hline
\end{tabular}

Note that transfer payments are not further distinguished in the model (and where adjusted using one single adjustment factor in italics)

Table 13 Sets in the CEPE model

\begin{tabular}{|c|c|}
\hline Symbol & Description \\
\hline $\begin{array}{l}i \in I=\text { agr, atp, benz, bme, che, cns, coa, cru, } \\
\text { edt, elt, est, ewi, fmp, gas, hoil, hwi, mch, } \\
\text { med, nme, nuc, omc, omop, pap, pla, trd, } \\
\text { veh, wht, ele, man, ser, trc, try\} }\end{array}$ & Industries \\
\hline$c \in C=\{h h$, reinvest $\}$ & $\begin{array}{l}\text { Representative household } \\
\text { and reinvestment activity }\end{array}$ \\
\hline$g \in G=I \cup C \cup\{$ govt, inv $\}$ & Industries and agents \\
\hline$f \in F=\{l a b, c a p\}$ & Production factors \\
\hline$h h \in H H=\{h 1, \ldots, h 9734\}$ & Households \\
\hline ets $\in E T S=\{$ pap, che, pla, nme, bme, fmp, & $\begin{array}{l}\text { Industries within the } \\
\text { emission trading system } \\
\text { (ETS) }\end{array}$ \\
\hline \multicolumn{2}{|l|}{ atp, coa, ele, ewi, hwi $\} \subset$ l } \\
\hline nets $\in$ NETS $=八$ ets & Non-ETS Industries \\
\hline$e \in E=\{$ benz, edt, omop, hoil, gas, coa $\} \subset$ l & Energy goods \\
\hline benz $=\{$ benz $\}$ & $\begin{array}{l}\text { Motor fuels (gasoline and } \\
\text { diesel) }\end{array}$ \\
\hline$e d t=\{e d t\}$ & $\begin{array}{l}\text { Electricity consumption } \\
\text { commodities }\end{array}$ \\
\hline $\mathrm{coa}=\{\mathrm{coa}\}$ & Coal commodities \\
\hline lq $=\{$ gas, omop, hoil, benz $\}$ & Liquid fuel commodities \\
\hline tec $\in T=\{$ ren, nuc, hyd, fos $\}$ & $\begin{array}{l}\text { Technologies for electricity } \\
\text { generation }\end{array}$ \\
\hline
\end{tabular}


Table 14 Variables in the CEPE model

\begin{tabular}{|c|c|}
\hline Symbol & Description \\
\hline \multicolumn{2}{|c|}{ Activity levels } \\
\hline$Y_{g}$ & Creation of industrial output or household utility \\
\hline$Y X_{g}$ & Transformation of output to domestic supply or exports \\
\hline$A_{i}$ & Armington aggregate of domestic supply and imports \\
\hline$A S_{i, g}$ & Market demand of good $i$ by sector/consumer $g$ \\
\hline$M_{i}$ & Imports \\
\hline$W_{c}$ & Welfare from consumption \\
\hline KM & Imports of capital services \\
\hline KX & Exports of capital services \\
\hline$L D_{i}$ & Labor demand by industry $i$ \\
\hline$L S_{C}$ & Labor supply by aggregate household \\
\hline$K D_{i}$ & Demand for capital services by industry $i$ \\
\hline$K S_{C}$ & Supply of capital services by aggregate household \\
\hline$A S E_{i, t e c}$ & Market demand of good $i$ by technology tec \\
\hline$K E S_{\text {tec, }, \mathrm{C}}$ & Supply of technology-specific capital services by household \\
\hline$E^{E T E C}$ tec & Electricity generation \\
\hline$N C M_{C}$ & Household income \\
\hline \multicolumn{2}{|c|}{ Commodity prices } \\
\hline$P W_{c}$ & Price of household utility \\
\hline$P_{g}$ & Price of activity $g$ \\
\hline$P D_{g}$ & Price of domestic supply \\
\hline$P A_{i}$ & Price of Armington commodity $i$ \\
\hline PATE $i$, tec & Price of Armington commodity after taxes \\
\hline PATS $_{i, g}$ & Price of Armington commodity after taxes \\
\hline$P M_{i}$ & Price of imports of commodity $i$ \\
\hline PFX & Price of foreign exchange \\
\hline$P L$ & Gross wage rate \\
\hline$P L S_{C}$ & Net employee wage rate \\
\hline RK & Gross rental rate of capital \\
\hline$R_{K S}$ & Net rental rate of capital \\
\hline$R K E_{\text {tec }}$ & Gross rent of tec specific capital \\
\hline RKES $_{\text {tec, }, \mathrm{c}}$ & Net rent of tec specific capital \\
\hline$P F D_{f, i}$ & Price of production factor $f$ in industry $i$ \\
\hline$P I N C_{C}$ & Price index of household income \\
\hline$P C O 2^{E T S}$ & Permit price in the Swiss ETS \\
\hline PCO2 & Price of $\mathrm{CO}_{2}$ emissions from $\mathrm{CO}_{2} 2$ tax \\
\hline PEDT & $\begin{array}{l}\text { Price of energy from energy taxation in standardized energy } \\
\text { services }\end{array}$ \\
\hline PMOT & Mineral oil tax \\
\hline \multicolumn{2}{|c|}{ Consumers } \\
\hline$R A_{c}$ & Representative household \\
\hline GOVT & Government (tax revenue agent) \\
\hline \multicolumn{2}{|c|}{ Auxiliary variables } \\
\hline PINDEX & Consumer price index \\
\hline EMICARB & Emissions outside ETS under $\mathrm{CO}_{2}$ tax \\
\hline$M \cup_{e}^{E}$ & Energy demand under tax on energy good e \\
\hline REC $C^{L S}$ & $\begin{array}{l}\text { Volume of transfers for compensating households for carbon } \\
\text { and energy tax }\end{array}$ \\
\hline$R E C^{L T}$ & $\begin{array}{l}\text { Reduction in labor tax rate for compensating households for } \\
\text { carbon and energy tax }\end{array}$ \\
\hline RECVAT & $\begin{array}{l}\text { Reduction in value-added tax rate for compensating house- } \\
\text { holds for carbon and energy tax }\end{array}$ \\
\hline
\end{tabular}


Table 14 Variables in the CEPE model (Continued)

\begin{tabular}{|c|c|}
\hline Symbol & Description \\
\hline$R E C^{W}$ & $\begin{array}{l}\text { Wage subsidy rate for compensating industries outside the ETS } \\
\text { for carbon and energy tax }\end{array}$ \\
\hline RECWETS & $\begin{array}{l}\text { Wage subsidy rate for compensating industries in ETS for ETS } \\
\text { permit expenditures and energy tax }\end{array}$ \\
\hline QMOT & Provision of implicit permits that determines mineral oil tax \\
\hline REINVEST & Budget adjustment for keeping investment constant \\
\hline REVT & Revenue generating tax on net household income \\
\hline
\end{tabular}

The $\mathrm{CO}_{2}$ tax on non-ETS emissions is set endogenously, in order to restrict national emissions according to the overall emission target. The model achieves this by restricting the amount of $\mathrm{CO}_{2}$ that is allowed to be emitted through the parameter $E M I C A R B$ and lets the market balance for $P C O 2$ set the corresponding carbon tax:

cbauemi $\cdot E M I C A R B \geq$ emitarget-etscap

$\perp E M I C A R B \geq 0$.

In scenarios where all emissions are taxed uniformly, etscap $=0$.

The tax on electricity is a tax on physical quantities as well and has to be pegged to the national price indexed PINDEX by setting the variable $M U^{E}$ :

$$
\text { enetax }_{\text {edt }} \cdot P I N D E X \geq P E D T \quad \perp \quad M U_{\text {edt }}^{E} \geq 0 .
$$

In scenarios where revenue from taxing carbon emissions and energy demand of households is recycled through lump-sum payments, the volume of these payments is determined by $R E C^{\mathrm{LS}}$ by

$$
\begin{aligned}
R E C^{\mathrm{LS}} \cdot P F X & \geq \sum_{i}\left(A S_{i, \mathrm{hh}} \cdot c o 2_{i, \mathrm{hh}} \cdot P C O 2 \cdot \text { mult }_{i}\right) & \\
& +A S_{\text {edt,hhene }} \text { edt,hh } P E D T & \perp R E C^{\mathrm{LS}} \geq 0 .
\end{aligned}
$$

In scenarios where revenue from taxing carbon emissions and energy demand of households is recycled through lumpsum payments, the volume of these payments is determined by $R E C^{\mathrm{LT}}$ by

$$
\begin{array}{rlrl}
R E C^{\mathrm{LT}} P L \sum_{c} \text { evom }_{\mathrm{lab}, c} L S_{c} & \geq \sum_{i}\left(A S_{i, \mathrm{hh}} \cdot c o 2_{i, \mathrm{hh}} \cdot P C O 2 \cdot \text { mult }_{i}\right) & & \\
& +A S_{\mathrm{edt}, \mathrm{hh}} \text { ene }_{\mathrm{edt}, \mathrm{hh}} P E D T & \perp \quad R E C^{\mathrm{LT}} \geq 0 .
\end{array}
$$

In scenarios where revenue from taxing carbon emissions and energy demand of households is recycled through lumpsum payments, the volume of these payments is determined by $R E C^{\mathrm{VAT}}$ by

$$
\begin{array}{rlr}
R E C^{\mathrm{VAT}} & \sum_{i \in\{\mathrm{agr}, \mathrm{trc}\}, g} A S_{i, g} P A_{i}\left(\text { vafm }_{i, g}-v \operatorname{tax}_{i, g}\right) & \\
& \geq \sum_{i}\left(A S_{i, \mathrm{hh}} \cdot c o 2_{i, \mathrm{hh}} \cdot P C O 2 \cdot \text { mult }_{i}\right) & \\
& +A S_{\mathrm{edt}, \mathrm{hh}} \text { ene }_{\mathrm{edt}, \mathrm{hh}} P E D T & \perp R E C^{\mathrm{VAT}} \geq 0 .
\end{array}
$$


Table 15 Model parameters

\begin{tabular}{|c|c|}
\hline Symbol & Description \\
\hline \multicolumn{2}{|c|}{ Elasticity of substitution parameters } \\
\hline$\sigma_{i}^{\top}$ & $\begin{array}{l}\text { Elasticity of transformation between domestic and export } \\
\text { markets }\end{array}$ \\
\hline$\sigma_{i}^{A}$ & Domestic-imported composite in domestic market \\
\hline$\sigma_{c}^{\text {topc }}$ & Top level (transport-non-transport composite) \\
\hline$\sigma_{c}^{a t}$ & Transport composite \\
\hline$\sigma_{g}^{k l e \_m}$ & Value-added-energy-material composite \\
\hline$\sigma_{g}^{m}$ & Material composite \\
\hline$\sigma_{i}^{k l \_} e$ & Value-added-energy composite \\
\hline$\sigma_{i}^{k}-1$ & Value-added composite \\
\hline$\sigma_{g}^{c g o \_e l e}$ & Energy composite \\
\hline$\sigma_{g}^{c_{-} g o}$ & Fossil fuel composite \\
\hline$\sigma_{g}^{g-o}$ & Liquid fuel and gas composite \\
\hline$\sigma_{\text {tec }}^{E L E}$ & Capital-O\&M composite in electricity generation \\
\hline \multicolumn{2}{|c|}{ Input and expenditure shares } \\
\hline$\theta_{D, i}^{Y X}$ & Share of supply to domestic market \\
\hline$\theta_{a t, c}^{\text {topc }}$ & Share of transport nest in total expenditures \\
\hline$\theta_{k l e \_m, c}^{\text {topc }}$ & Share of value added and energy in total expenditures \\
\hline$\theta_{j, c}^{a t}$ & Shares of commodity $j$ in public transport cost bundle \\
\hline$\theta_{m, \bar{g}}^{k l e \_m}$ & Share of materials in kle_m \\
\hline$\theta_{j, g}^{m}$ & Shares of commodity $j$ in material cost bundle \\
\hline$\theta_{\text {edt }, g}^{\text {cgo_ele }}$ & Share of electricity in energy bundle \\
\hline$\theta_{\mathrm{COa}, 9}^{\mathrm{c} g \mathrm{go}}$ & Share of coal in fossil fuel bundle \\
\hline$\theta_{j, 9}^{g-o}$ & Share of commodity $j$ in liquid fuel bundle \\
\hline$\theta_{k-1, i}^{k l \_e}$ & Share of value-added cost in value-added/energy composite \\
\hline$\theta_{f, i}^{k} l$ & Share of production factor $f$ in value-added composite \\
\hline$\theta_{D, i}^{A}$ & Share of market supply from domestic supply \\
\hline$\theta_{K, t e c}^{E L L E}$ & Share of capital rents in generation costs \\
\hline$\theta_{L, C}^{I N C}$ & Value share of wage earnings in income \\
\hline$\theta_{K, C}^{I N C}$ & Value share of capital rents in income \\
\hline$\theta_{K E, t e c, C}^{I N C}$ & Value share of electricity capital rents in income \\
\hline$\theta_{T, C}^{I N C}$ & Value share of transfers in income \\
\hline \multicolumn{2}{|c|}{ Baseline variable values } \\
\hline$\overline{p s_{s t, c}}$ & Baseline prices of energy services \\
\hline$\overline{\text { pats }_{j, g}}$ & Baseline prices of market goods \\
\hline$\overline{p f d_{f, i}}$ & Baseline factor prices \\
\hline \multicolumn{2}{|c|}{ Other parameters } \\
\hline$s t d_{s t}$ & Standardized energy use per million CHF \\
\hline$p^{\mathrm{CO} 2}$ & EU ETS permit price in $\mathrm{CHF}$ per tonne $\mathrm{CO}_{2}$ \\
\hline$p_{i}^{T R D}$ & World market prices \\
\hline$r t v a i, g$ & Value-added tax rate \\
\hline rtoth $_{i, g}$ & Net rate of other taxes \\
\hline$r t_{m o t}$ & Baseline ad valorem mineral oil tax rate \\
\hline$\phi_{i, g}^{\mathrm{CO} 2}$ & $\mathrm{CO}_{2}$ intensity of commodity value \\
\hline$\phi_{i, g}^{\mathrm{MOT}}$ & Mineral oil tax intensity of commodity value \\
\hline
\end{tabular}


Table 15 Model parameters (Continued)

\begin{tabular}{|c|c|}
\hline Symbol & Description \\
\hline mult $_{i}$ & Fuel specific multiplier on $\mathrm{CO}_{2}$ tax \\
\hline$\phi_{i, g}^{E D T}$ & Electricity intensity of commodity value \\
\hline$e_{e, s t}$ & Energy content of good $e$ \\
\hline vom $_{g}$ & Baseline output of activity $g$ \\
\hline $\mathrm{vid}_{c}$ & Baseline investment demand \\
\hline vex $_{i}$ & Baseline exports \\
\hline $\operatorname{vim}_{i}$ & Baseline imports \\
\hline $\operatorname{vafm}_{i, g}$ & Baseline intermediates demand \\
\hline $\operatorname{vam}_{i}$ & Baseline market supply \\
\hline $\operatorname{vtax}_{i, g}$ & Baseline commodity tax payments \\
\hline$d e d t$ & Baseline national energy demand \\
\hline ene $_{e, g}$ & Baseline energy demand \\
\hline etscap & Emission cap for Swiss ETS \\
\hline $\mathrm{co}_{e, g}$ & $\mathrm{CO}_{2}$ content of energy demand by $\mathrm{g}$ \\
\hline cemi & Baseline non-ETS emissions \\
\hline vist $_{\text {st }, i}$ & Baseline supply of intermediates for energy services \\
\hline vidst & Baseline demand for intermediates for energy services \\
\hline$v f m_{f, i}$ & Baseline factor demand \\
\hline $\operatorname{evom}_{f, c}$ & Baseline factor endowment \\
\hline $\operatorname{vinc}_{c}$ & Baseline income \\
\hline tcorr hh & Difference marginal and average income tax rate times income \\
\hline $\operatorname{trf} f_{\text {hh }}$ & Benchmark transfers \\
\hline$v b$ & Benchmark balance of trade \\
\hline mrtincf $f_{\text {,hh }}$ & Marginal income tax rate on factor $f$ \\
\hline mrtinctectec,hh & Marginal income tax rate on tec specific capital \\
\hline mvtfinc $_{f, \mathrm{hh}}$ & Marginal income tax rate times income for factor $f$ \\
\hline$v t f$ lab,hh & Volume of social security contributions \\
\hline mrtlinc nhe $_{\text {nh }}$ & Income tax on labor income based on net income \\
\hline$r t i_{i}$ & Tariff rate on imports \\
\hline$r t f_{f, i}$ & Tax rate on factor demand \\
\hline$r t f_{, t e c}^{e}$ & $\begin{array}{l}\text { Tax rate on factor demand by power generation } \\
\text { technologies }\end{array}$ \\
\hline$r t f h h_{\text {lab,hh }}$ & Tax rate labor provision \\
\hline rtavrowi & VA tax rate on exports \\
\hline $\operatorname{vtavi,g}_{i, g}$ & Baseline value of ad valorem taxes \\
\hline rtavi,g $_{i, g}$ & Net rate of ad valorem taxes \\
\hline$v t^{\prime m} o_{i, g}$ & Baseline value of mineral oil taxes \\
\hline emitarget & National target for $\mathrm{CO}_{2}$ emissions \\
\hline cbauemi & Baseline emissions outside ETS \\
\hline $\operatorname{co2tax}$ & Exogenous $\mathrm{CO}_{2}$ tax \\
\hline eletarget & National target for electricity demand \\
\hline enetax $_{\text {edt }}$ & Tax on electricity \\
\hline target $t_{\text {tec }}^{K E V}$ & Technology-specific targets for market shares under KEV \\
\hline$r t m o i, g$ & Baseline mineral oil tax rate \\
\hline
\end{tabular}


Revenue from taxing non-ETS industries is recycled with a subsidy $R E C^{W}$ on wage payments:

$$
\begin{array}{rlr}
R E C^{W} & \sum_{g \in G \backslash \text { ets }}\left(L D_{g} \cdot v f m_{\mathrm{lab}, g} \cdot P F D_{\mathrm{lab}, g}\right) & \\
\geq \sum_{i \in I, g \in I \backslash \text { ets }}\left(A S_{i, g} \cdot\left(c o 2_{i, g} \cdot P C O 2 \cdot \text { mult }_{i}+\text { ene }_{i, g} P E D T\right)\right) & \perp R E C^{W} \geq 0 .
\end{array}
$$

The subsidy $R E C^{W E T S}$ serves the same purpose for levies on ETS industries. It is set accordingly:

$$
\begin{aligned}
R E C^{W E T S} & \sum_{g \in e t s}\left(L D_{g} \cdot v f m_{\mathrm{lab}, g} \cdot P F D_{\mathrm{lab}, g}\right) \\
\geq & \sum_{i \in I, g \in(I \cap e t s)}\left(A S_{i, g} \cdot\left(c o 2_{i, g} \cdot P C O 2^{E T S}+e n e_{i, g} \cdot P E D T\right)\right) \\
& +\sum_{i, t e c}\left(A S E_{i, t e c}\left(c o 2_{i, t e c}^{e} \cdot P C O 2^{E T S}+e n e_{i, t e c}^{e} \cdot P E D T\right)\right)
\end{aligned}
$$$$
\perp R E C^{W E T S} \geq 0 .
$$

Changes in tax income and price changes make it necessary to adjust government income GOVT such that government can afford to purchase the same amounts of goods as in the baseline. This is achieved by taxing/subsidizing households' after tax income at rate REVT

$$
G O V T \geq P D_{\text {govt }} \cdot \text { vom }_{\text {govt }}
$$

$\perp \quad R E V T \geq-0.999999$.

Excise tax rates on mineral oil are not ad valorem but tied to physical quantities. The model accounts for this by counting the physical quantities in terms of taxed value and ensuring that the tax rate is indexed by the national price index PINDEX:

$$
P M O T \geq P I N D E X
$$

$$
\perp \quad Q M O T \geq 0 .
$$

The reinvestment of capital rents is done by the agent reinvest who has the budget $R A_{\text {reinvest }}$. In order to operate, this agent demands services from the sector ser. The model fixes this demand by adjusting reinvest's budget through the variable REINVEST according to 


\section{Abbreviations}

BAU: Business as usual; CEPE-HH: Name of the numerical model used for this study; CGE: Computable general equilibrium; CH ETS: Swiss Emission Trading System; $\mathrm{CO}_{2}$ : Carbon dioxide; EU ETS: European Emission Trading System; GDP: Gross domestic product; GHG: Greenhouse gas; MEl: Mean equivalent income; MI: Mean income; MPS/GE: Mathematical Programming System for General Equilibrium Analysis; SEMP: Swiss Energy Modelling Platform; VAT: Value-added tax

\section{Acknowledgments}

The author acknowledges significant contributions by Mirjam Kosch, Sebastian Rausch, and Renger van Nieuwkoop in the preparation and design of the underlying data and model for the SCCER-CREST. Sebastian Rausch provided additional helpful comments specific to this study.

\section{Authors' contributions}

All modeling work, analysis of the results, and writing specific to this study have been carried out by the author, Florian Landis. The author read and approved the final manuscript.

\section{Funding}

Florian Landis acknowledges financial support by Innosuisse, the Swiss Innovation Agency, through the Competence Center for Research in Energy, Society and Transition (SCCER-CREST)

\section{Availability of data and materials}

The data bases underlying the analysis are provided by the Swiss Statistical Office and are available to researchers upon signing confidentiality agreements. A description of the household budget survey and contacts to its administrators may be found at https://www.bfs.admin.ch/bfs/en/home/ statistics/economic-social-situation-population/surveys/hbs.html. Similarly, the input-output tables of Switzerland can be found at https://www.bfs. admin.ch/bfs/de/home/statistiken/volkswirtschaft/input-output.html. The numerical model is documented in the Appendix 3 of this paper.

\section{Competing interests}

The author declares that he has no competing interests.

Received: 13 December 2017 Accepted: 30 July 2019

Published online: 13 September 2019

\section{References}

Armington, $P$ (1969). A theory of demand for products distinguished by place of production. International Monetary Fund Staff Papers, 16, 159-76.

Atkinson, $A B$ (1970). On the measurement of inequality On the measurement of inequality. Journal of Economic Theory, 2(3), 244-263. https://doi.org/10 1016/0022-0531(70)90039-6.

Bethlehem, J, Cobben, F, Schouten, B (2011). Handbook of nonresponse in household surveys. Hoboken: Wiley.

BFS (2012a). Haushaltsbudgeterhebung 2009: Kommentierte Ergebnisse und Tabellen. Neuchâtel: Bundesamt für Statistik (BFS).

BFS (2012b). Haushaltsbudgeterhebung 2010: Kommentierte Ergebnisse und Tabellen. Neuchâtel: Bundesamt für Statistik (BFS).

BFS (2013). Haushaltsbudgeterhebung 2011: Kommentierte Ergebnisse und Tabellen. Neuchâtel: Bundesamt für Statistik (BFS).

BFS (2007). Die Einkommens- und Verbrauchserhebung mit neuer Methode. Neues Gewichtungsmodell, Resultate 2000-2003 und Studie zur Altersvorsorge. Neuchâtel: Bundesamt fûr Statistik (BFS).

Böhringer, C, Landis, F, Tovar Reaños, MA (2017). Economic Impacts of Renewable Energy Production in Germany. The Energy Journal, 38(01). https://doi.org/10.5547/01956574.38.S11.cboh.

Böhringer, C, \& Müller, A (2014). Environmental tax reforms in Switzerland: A computable general equilibrium impact analysis. Swiss Journal of Economics and Statistics, 150(1), 1-21.

Böhringer, C, Carbone, JC, Rutherford, T (2018). Embodied carbon tariffs. Scandinavian Journal of Economics, 120(1), 183-210.

Bovenberg, AL (1999). Green tax reforms and the double dividend: An updated reader's guide. International Tax and Public Finance, 6(3), 421-443. https://doi.org/10.1023/A:1008715920337.

Bovenberg, AL, \& Goulder, LH (1996). Optimal environmental taxation in the presence of other taxes: General-equilibrium analyses. The American Economic Review, 86(4), 985-1000.
Carattini, S, Baranzini, A, Thalmann, P, Varone, F, Vöhringer, F (2017). Green taxes in a post-paris world: Are millions of nays inevitable? Environmental and Resource Economics, 68(1), 97-128. https://doi.org/10.1007/s10640017-0133-8

Carlsson, F, Daruvala, D, Johansson-Stenman, O (2005). Are people inequality-averse, or just risk-averse? Economica, 72(287), 375-396. https:// doi.org/10.1111/j.0013-0427.2005.00421.X.

Creedy, J, \& Sleeman, C (2006). The distributional effects of indirect taxes: Models and applications from New Zealand. Cheltenham, UK; Northampton, MA: Edward Elgar Publishing.

Decoster, A (1995). A microsimulation model for Belgian indirect taxes with a carbon/energy tax illustration for Belgium. Tijdschrift voor economie en management, 40(2), 133-156.

Dirkse, SP, \& Ferris, MC (1995). The PATH solver: A non-monontone stabilization scheme for mixed complementarity problems. Optimization Methods and Software, 5, 123-156.

Fehr, E, \& Schmidt, KM (1999). A theory of fairness, competition, and cooperation. The Quarterly Journal of Economics, 114(3), 817-868. https:// doi.org/10.1162/003355399556151.

Goulder, LH (1995). Environmental taxation and the double dividend: A reader's guide. International Tax and Public Finance, 2(2), 157-183. https:// doi.org/10.1007/BF00877495.

Harrison, GW, Rutherford, TF, Tarr, DG (1997). Quantifying the Uruguay round. The Economic Journal, 107(444), 1405-1430.

Imhof, J (2012). Fuel exemptions, revenue recycling, equity and efficiency: evaluating post-Kyoto policies for Switzerland. Swiss Journal of Economics and Statistics, 148(2), 197-227.

Landis, F, \& Heindl, P (2016). Renewable energy targets in the context of the EU ETS: Whom do they benefit exactly? (Tech. Rep. No. 16-026) Mannheim: ZEW.

Landis, F, Marcucci, A, Rausch, S, Kannan, R, Bretschger, L (2018). Multi-model comparison of Swiss Decarbonization Scenarios. Swiss Journal of Economics and Statistics. https://doi.org/10.1186/s41937-019-0040-8.

Landis, F, Rausch, S, Kosch, M (2018). Differentiated carbon prices and the economic cost of decarbonization. Environmental and Resource Economics, 70(2), 483-516. https://doi.org/10.1007/s10640-017-0130-y.

Landis, F, Rausch, S, Kosch, M, Böhringer, C (2017). Efficient and equitable policy design: Taxing energy use or promoting energy savings? Energy Journal, 40(1), 73-104.

Layard, R, Mayraz, G, Nickell, S (2008). The marginal utility of income. Journal of Public Economics, 92(8), 1846-1857. https://doi.org/10.1016/j.jpubeco. 2008.01.007.

Mathiesen, L (1985). Computation of economic equilibria by a sequence of linear complementarity problems. Mathematical Programming Study, 23, 144-162.

Nathani, C, Sutter, D, van Nieuwkoop, R, Kraner, S, Peter, M, Zandonella, R (2013). Energiebezogene Differenzierung der Schweizerischen IOT 2008 und Revision der Energie-IOT 2001 und 2005. Schlussbericht an das Bundesamt für Energie. Bern: Bundesamt für Energie (BFE).

Rausch, S, Metcalf, GE, Reilly, JM (2011). Distributional impacts of carbon pricing: A general equilibrium approach with micro-data for households. Energy Economics, 33(Supplement 1), S20-S33. https://doi.org/10.1016/j. eneco.2011.07.023

Rubin, DB (1987). Multiple imputation for nonresponse in surveys. New York: Wiley.

Rutherford, TF (1995). Extension of GAMS for complementarity problems arising in applied economics. Journal of Economic Dynamics and Control, 19(8), 1299-1324.

Rutherford, TF (1999). Applied general equilibrium modeling with MPSGE as a GAMS subsystem: an overview of the modeling framework and syntax. Computational Economics, 14, 1-46.

Rutherford, TF, \& Tarr, D (2008). Poverty effects of Russia's WTO accession: modeling "real" households with endogenous productivity effects. Journal of International Economics, 75(1), 131-150.

Speck, S (1999). Energy and carbon taxes and their distributional implications. Energy Policy, 27(11), 659-667. https://doi.org/10.1016/S03014215(99)00059-2.

Sterner, T (2012). Distributional effects of taxing transport fuel. Energy Policy, 41 , 75-83. https://doi.org/10.1016/j.enpol.2010.03.012.

Subramanian, S (2007). Indicators of inequality and poverty. In M McGillivray (Ed.), Human Well-Being: Concept and Measurement. https://doi.org/10. 1057/9780230625600_6 (pp. 135-166). London: Palgrave Macmillan UK.

\section{Publisher's Note}

Springer Nature remains neutral with regard to jurisdictional claims in published maps and institutional affiliations. 